\title{
Exosomal cell-to-cell transmission of alpha synuclein oligomers
}

\author{
Karin M Danzer ${ }^{1,3}$, Lisa R Kranich¹, Wolfgang P Ruf ${ }^{1}$, Ozge Cagsal-Getkin ${ }^{1,2}$, Ashley R Winslow ${ }^{1}$, Liya Zhu', \\ Charles R Vanderburg ${ }^{1,2}$ and Pamela J McLean ${ }^{1,4^{*}}$
}

\begin{abstract}
Background: Aggregation of alpha-synuclein (asyn) and resulting cytotoxicity is a hallmark of sporadic and familial Parkinson's disease (PD) as well as dementia with Lewy bodies, with recent evidence implicating oligomeric and pre-fibrillar forms of asyn as the pathogenic species. Recent in vitro studies support the idea of transcellular spread of extracellular, secreted asyn across membranes. The aim of this study is to characterize the transcellular spread of asyn oligomers and determine their extracellular location.
\end{abstract}

Results: Using a novel protein fragment complementation assay where asyn is fused to non-bioluminescent amino-or carboxy-terminus fragments of humanized Gaussia Luciferase we demonstrate here that asyn oligomers can be found in at least two extracellular fractions: either associated with exosomes or free. Exosome-associated asyn oligomers are more likely to be taken up by recipient cells and can induce more toxicity compared to free asyn oligomers. Specifically, we determine that asyn oligomers are present on both the outside as well as inside of exosomes. Notably, the pathway of secretion of asyn oligomers is strongly influenced by autophagic activity.

Conclusions: Our data suggest that asyn may be secreted via different secretory pathways. We hypothesize that exosome-mediated release of asyn oligomers is a mechanism whereby cells clear toxic asyn oligomers when autophagic mechanisms fail to be sufficient. Preventing the early events in asyn exosomal release and uptake by inducing autophagy may be a novel approach to halt disease spreading in PD and other synucleinopathies.

Keywords: Alpha synuclein, Oligomers, Exosomes, Parkinson's disease, Aggregation, Secretion

\section{Background}

Parkinson's disease (PD) is pathologically characterized by alpha-synuclein ( $\alpha$ syn) immunopositive intracellular deposits termed Lewy bodies [1]. Gene multiplication of the asyn gene [2,3] and missense mutations [4-6] are linked to familial forms of PD. Together, these data support a role for asyn in the pathogenesis of PD.

Because $\alpha$ syn inclusion body pathology associated with PD occurs in a hierarchical distribution with its epicenter in the brainstem, then extends to the mesolimbic cortex and associated areas [7], Braak et al. have suggested that $\alpha$ syn pathology spreads gradually throughout the neuraxis as PD progresses [8]. However, as yet, the

\footnotetext{
* Correspondence: mclean.pamela@mayo.edu

${ }^{1}$ MassGeneral Institute for Neurodegenerative Disease, Department of Neurology, Massachusetts General Hospital, Charlestown, MA, USA

${ }^{4}$ Present address: Department of Neuroscience, Mayo Clinic, 4500 San Pablo Rd, Jacksonville, FL 32224, USA

Full list of author information is available at the end of the article
}

underlying mechanisms of disease progression in PD remain to be determined.

The main component of Lewy bodies and Lewy neurites are fibrillar aggregates of asyn [1] but a growing body of evidence suggests that prefibrillar oligomers of asyn are key contributors in the progression of Parkinson's disease [9-15].

Until recently asyn was thought to exert its toxic effects intracellularly. However, this concept was challenged when El-Agnaf et al. detected asyn species in human plasma and CSF [12]. Furthermore, Desplats et al. demonstrated that $\alpha$ syn can be directly transmitted from neuronal cells overexpressing asyn to transplanted embryonic stem cells both in tissue culture and in transgenic animals [16]. Concurrently, our group was able to demonstrate that cell produced asyn oligomers are secreted and taken up by neighboring cells where they have detrimental consequences [17]. These results suggest that the pathogenic action of asyn oligomers are

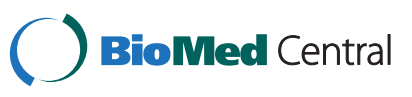


not limited to the donor cells but can extend into the extracellular space and affect neighboring cells. In support of this hypothesis, recombinant asyn oligomers added to cell culture medium have been shown to be internalized by recipient cells causing either cell death or seeding of asyn [18-22]. The mechanism(s) of $\alpha$ syn transmission from cell to cell that contribute to the spread of $\alpha$ syn pathology remain largely unknown. One intriguing question is how intracellularly generated $\alpha$ syn is released into the extracellular space. A first hint that asyn may be secreted by externalized vesicles that have hallmarks of exosomes was recently provided [23,24].

The aim of this current study is to characterize $\alpha$ syn associated with exosomes and to explore the nature of asyn secretion using a highly sensitive protein complementration assay [25-30]. Moreover, we examine the specific relationship of asyn oligomers with exosomes and find that both intra-and extra-exosomal associated asyn oligomers exist. The importance of intact exosomes for re-uptake of $\alpha$ syn oligomers into neighboring cells and the role of autophagic activity on exosomal secretion of $\alpha$ syn oligomers are also examined.

\section{Results}

\section{Alpha-synuclein oligomers are found in exosomes}

Increasing evidence suggests that $\alpha$ syn can be released by neurons and neuronal like cells [17,31-33] although extracellular $\alpha$ syn and its pathological relevance are still hotly debated in the field. Recent work from our own group and the elegant study from Desplats et al. suggest that asyn can be transferred from cell to cell and thus may provide an explanation for the spread of $\alpha$ syn pathology in PD patients [16,17]. However, little is known about the mechanism of $\alpha$ syn secretion.

Recently, secretion of asyn in association with membrane vesicles, identified as exosomes based on their composition and biophysical properties, has been described $[23,24]$. However, the specific $\alpha$ syn species (monomers vs pathogenic oligomers) secreted with exosomes and the location of $\alpha$ syn remains to be determined.

To investigate whether oligomeric species of $\alpha$ syn are present in the exosome enriched fractions we employed a bioluminescent protein-fragment complementation assay $[25,26,30]$. In this strategy, $\alpha$ syn was fused to nonbioluminescent amino-terminal (S1) or carboxy-terminal fragments (S2) of Gaussia princeps luciferase [28] that can reconstitute when brought together by $\alpha$ syn- $\alpha$ syn interactions [25], thus providing a readout of $\alpha$ syn oligomerization (Additional file 1: Figure S1A). The same principle of protein complementation with fluorescent venus YFP was used generating the fluorescent protein-fragment complementation pair V1S or SV2 whereby N-terminal half of Venus YFP is fused to the $\mathrm{N}$-terminus of asyn (V1S) and C-terminal half of Venus
YFP is fused to the C-terminus of asyn (SV2) [25] (Additional file 1: Figure S1B).

Human H4 neuroglioma cells were co-transfected with S1 and S2 that reconstitute luciferase activity upon $\alpha$ syn oligomerization. Exosomes were isolated from conditioned media (CM) of $\mathrm{H} 4$ cells using an established subcellular fractionation methodology [34,35] and the exosomal pellet was analyzed for luciferase activity that is indicative of $\alpha$ syn oligomers. Interestingly, we witnessed a large increase in luciferase activity in the exosomal fraction derived from $\mathrm{H} 4$ cells transfected with $\mathrm{S} 1$ and S2 compared to exosomes from mock transfected cells (Figure 1A), suggesting that asyn, and specifically asyn oligomers are present in the exosomal fraction. To exclude the possibility that $\mathrm{N}$ - or C-terminal fragments of human Gaussia Luciferase can interfere with protein sorting in exosomes, our results were verified in exosomes isolated from human $\mathrm{H} 4$ cells transfected with untagged wild-type (wt) asyn using a human asyn ELISA. Significant levels of $\alpha$ syn were present in the exosomal fraction from wt $\alpha$ syn and S1/S2 transfected H4 cells compared to exosomes derived from empty vector (mock) transfected cells (Figure 1B).

We extended these observations to primary cortical neurons where asyn oligomers were also found in the exosomal fraction isolated from primary neurons cotransduced with adeno-associated virus (AAV) encoding S1 (AAV-S1) and S2 (AAV-S2) as demonstrated by a significant increase in luciferase activity compared to exosomes isolated from naive neurons (Figure 1C). In accord with the experiments performed in $\mathrm{H} 4$ cells, we also confirmed the presence of $\alpha$ syn in exosomes derived from primary neurons infected with a variety of different AAV constructs encoding either $\alpha$ syn-ires-GFP, AAV-S1 and AAV-S2 or asyn-venusYFP fluorescent proteinfragment complementation pair (AAV8-V1S or AAV8SV2) (Figure 1D) using an asyn ELISA. Taken together, our data provide evidence that asyn oligomers are present in the exosomal fractions from both neurons and non-neuronal cells.

\section{Characterization of exosomes}

To confirm the presence of exosomes, fractions from both primary neurons and $\mathrm{H} 4$ cells were subjected to SDS-PAGE and immunoblotting. All exosomal fractions were found to be immunopositive for the exosomespecific proteins alix and flotillin, whereas the 'exosomefree' supernatant was immuno-negative for alix and flotillin (Figure 2A).

Moreover, exosome-enriched fractions isolated from $\mathrm{CM}$ of $\mathrm{H} 4$ cells transfected with the $\alpha$ syn complementation pair S1 and S2 were also analyzed using electron microscopy and demonstrated the distinctive vesicular morphological structures characteristic of exosomes 

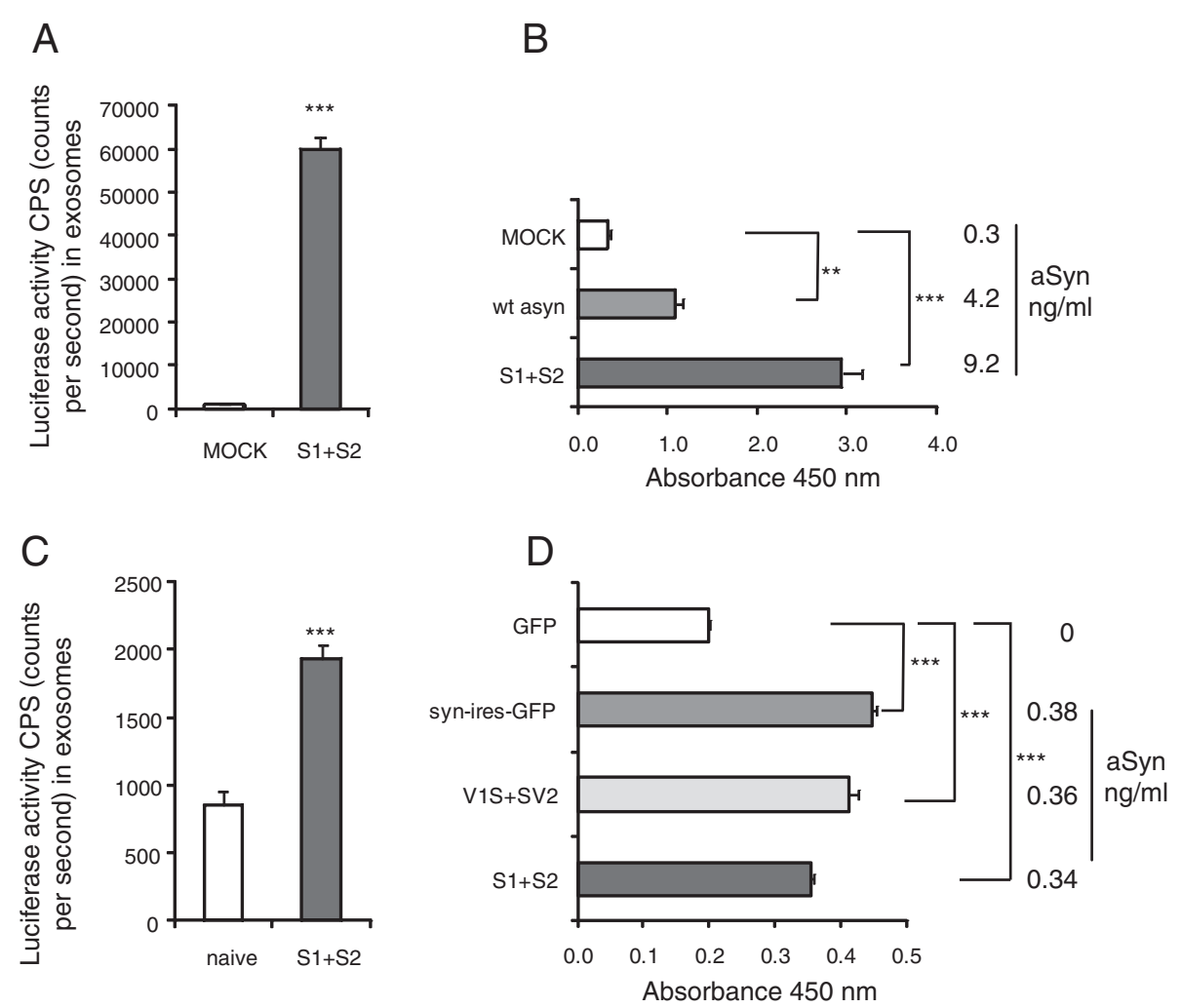

Figure 1 Extracellular aSyn oligomers are associated with exosomes: (A) Exosomal fractions from human $\mathrm{H} 4$ cells transfected with asyn complementation pair S1 and S2 contain high amounts of asyn oligomers, analyzed with a luciferase assay. Signal corresponds to $1.25 \times 100 \mathrm{~mm}$ dishes. $\mathrm{n}=6$, unpaired $\mathrm{t}$ test with Welch's correction, ${ }^{* * *} \mathrm{p}<0.001$ (B) asyn ELISA analysis from exosomal fractions from human H4 cells transfected with S1/S2, wt asyn or Mock. Signal corresponds to $1 \times 100 \mathrm{~mm}$ dish. $\mathrm{n}=4$, unpaired t test with Welch's correction, ${ }^{* * *} \mathrm{p}<0.001$ (C) Exosomal fractions from primary neurons infected with asyn complementation pair S1 and S2 contain high amounts of asyn oligomers, analyzed with a luciferase assay, signal corresponds to $1 \times 60 \mathrm{~mm}$ dish, $n=4$, unpaired t test with Welch's correction, ${ }^{* * *} \mathrm{p}<0.001$ (D) asyn ELISA analysis from exosomal fractions from primary neurons infected with AAV expressing GFP, asyn -ires-GFP, V1S/SV2 and S1/S2. Values correspond to $1 \times 60 \mathrm{~mm}$ dish, $\mathrm{n}=4$, Tukey's Multiple Comparison Test, ${ }^{* *} \mathrm{p}<0.001$.

(Figure 2B). Immuno-electron microscopy with an antibody against the exosomal marker CD63 [36], confirmed characteristic exosomal vesicles typically $60-100 \mathrm{~nm}$ in size in exosome enriched fractions from $\mathrm{CM}$ of primary neurons co-transduced with AAV expressing the asyn complementation pair V1S or SV2 (Figure 2C).

Because microRNAs (miRs) have been found in exosomes [37], miR profiling is a powerful tool to definitively characterize exosomes. Exosome fractions from both S1/S2 transfected $\mathrm{H} 4$ cells and primary neurons transduced with AAV- $\alpha$ syn-ires-GFP were found to contain a large number of miRs that have previously been reported to be present in exosomes (see Tables 1 and 2). Of interest, we did not detect miR-7, which has been previously identified as a negative regulator of $\alpha$ syn expression [66].

Localization of asyn oligomers in the extracellular space Cytosolic proteins can be secreted from cells via at least two distinct pathways which include exocytosis and fusion of multi-vesicular bodies with the plasma membrane to release exosomes. Defining the localization of asyn in the extracellular space will provide insight into the mechanisms and pathways involved in asyn release. To examine the localization of asyn oligomers in the extracellular space we first digested exosome-enriched fractions containing asyn S1/S2 oligomers with $0.25 \%$ trypsin. Interestingly, trypsin digestion significantly reduced luciferase activity in the exosome fraction by $62 \%$ (Figure 3A) suggesting the presence of asyn oligomers either on the external surface of the exosomes or outside of exosomes. However, trypsin treatment did not eliminate luciferase activity to background levels completely, indicating that $\alpha$ syn oligomers must exist in the lumen of the exosomes that are insensitive to the trypsin treatment. To further clarify, we cotreated exosome fractions with trypsin and the detergent saponin $(0.1 \%)$. The presence of saponin results in exosome-membrane permeabilization. Notably, we saw a complete elimination of luciferase activity in the presence of trypsin and 
A

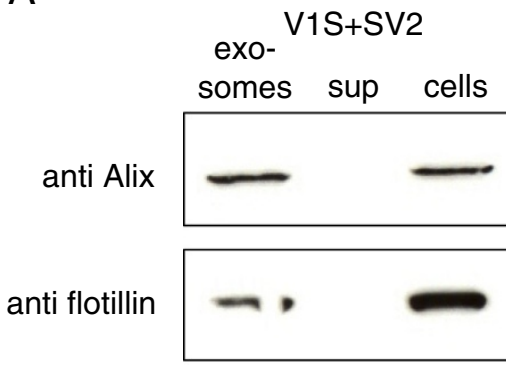

$105 \mathrm{kDa}$

$48 \mathrm{kDa}$

$\mathrm{S} 1+\mathrm{S} 2$

exo-

somes sup cells

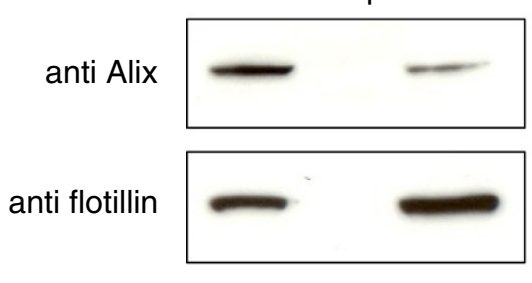

$105 \mathrm{kDa}$

$48 \mathrm{kDa}$

exo-

Syn-ires-GFP

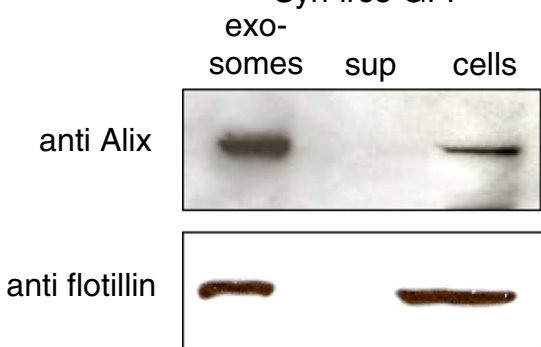

$105 \mathrm{kDa}$

$48 \mathrm{kDa}$
B

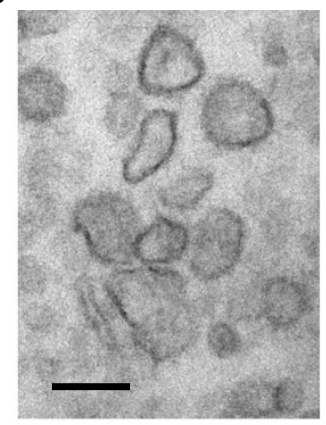

C

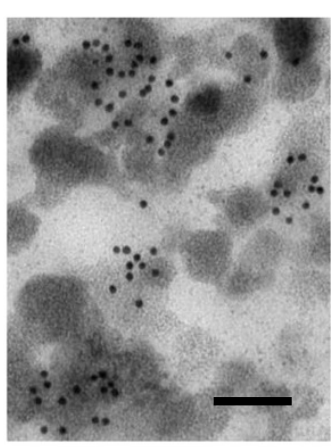

Figure 2 Characterization of exosomes: (A) Exosomal pellets derived from primary neurons infected with AAV-V1S/SV2, AAV-S1/S2, AAV- asyn-ires-GFP were resuspended in 1xPBS and analyzed by Western blotting using exosome specific antibodies anti Alix and anti flotillin. Also total cell lysates and exosome free supernatant (sup) were loaded as positive and negative controls, respectively. (B) Exosomes from S1/S2 transfected $\mathrm{H} 4$ cells were prepared as described before. After fixation vesicles were negatively stained with $2 \%$ uranyl acetate and observed under electron microscopy. Scale bar, $100 \mathrm{~nm}$. (C) Exosomes from primary neurons infected with AAV-V1S/SV2 were negatively stained with 2\% uranyl acetate and immunolabeled with CD63 antibody as exosomal marker. Scale bar, $100 \mathrm{~nm}$.

saponin (Figure 3A). Treatment with saponin alone slightly increased luciferase activity compared to untreated control exosomes, although it was not a significant increase. This could be due to enhanced substrate availability to lumenal $\alpha$ syn oligomers. The same experimental paradigm was tested on the "exosome-free" supernatant fraction. As expected, trypsin eliminated all luciferase activity from "free" $\alpha$ syn oligomers in the supernatant fraction in the presence or absence of saponin (Figure 3B). These data confirm the absence of exosomes from the supernatant fraction and verify that the experimental paradigm is sufficient to digest all available asyn oligomers.

To confirm our results on the localization of $\alpha$ syn oligomers inside/outside exosomes we examined samples prepared under the same experimental conditions using dot blot immunoblotting. Probing with Syn-1 antibody showed that exsosome free $\alpha$ syn oligomers (sup) were completely digested by trypsin independent of saponin treatment (lane 1, sup, Figure 3C). In contrast, Syn-1 signal was not completely eliminated when exosome fractions were treated with trypsin (lane 2, exo, Figure 3C). Only the combination of trypsin and saponin resulted in a complete digestion of asyn oligomers and a consequent abolishment of $\alpha$ syn immunostaining in exosome fractions. Probing with an antibody against the exosomal marker CD63, which is known to be located solely on the outside of exosomes, shows reactivity only in the exosome fractions not treated with trypsin and no reactivity at all in supernatant-associated $\alpha$ syn oligomers. 
Table 1 MicroRNA profiling of alpha-synuclein containing exosomes from $\mathrm{H} 4$ cell culture media

\begin{tabular}{|c|c|c|c|}
\hline miRNAs & function & remarks & Key citations \\
\hline $7 b$ & Inhibition of cell cycle progression and growth of melanoma cells & present in exosomes & {$[38,39]$} \\
\hline $7 i$ & regulatory responses to microbial infection & present in exosomes & {$[40,41]$} \\
\hline $18 b$ & exocytosis, angiogenesis, hematopoiesis, tumorgenesis & present in exosomes & [40] \\
\hline 182 & Repression of tumor suppressors & present in exosomes & {$[39,42]$} \\
\hline 184 & Block of NFAT1 protein expression & present in exosomes & {$[40,43]$} \\
\hline $363^{*}$ & - & & {$[44,45]$} \\
\hline $373^{*}$ & Involvement in tumor migration and invasion & present in exosomes & {$[39,46]$} \\
\hline 375 & exocytosis, angiogenesis, hematopoiesis, tumorgenesis & present in exosomes & {$[39,40]$} \\
\hline $376^{*}$ & - & & {$[47,48]$} \\
\hline 424 & controlling the macrophage differentiation program & present in exosomes & {$[39,49]$} \\
\hline 431 & - & CNS specific miRNA & {$[47,50]$} \\
\hline 455 & - & & [51] \\
\hline $487 a$ & Role in angiogenesis and cell aging & & [52] \\
\hline 492 & - & & [44] \\
\hline 494 & regulation of PTEN expression and functions as a micro-oncogene in carcinogenesis & present in exosomes & {$[39,53]$} \\
\hline $518 c$ & - & & {$[44,54]$} \\
\hline
\end{tabular}

Dot blots were also performed on fractions prepared from CM of cells transfected with wt untagged $\alpha$ syn. As expected, trypsin treatment resulted in a reduction in Syn-1 signal in exosome associated $\alpha$ syn oligomers but only the combination of trypsin and saponin resulted in a complete digestion and abolishment of Syn-1 signal. Together, the data indicate that $\alpha$ syn oligomers are located on the inside and outside of exosomes.

Table 2 MicroRNA profiling of alpha-synuclein containing exosomes from primary cortical neuron media

\begin{tabular}{|c|c|c|c|}
\hline miRNAs & function & remarks & Key citations \\
\hline $27 a$ & activating the expression of P-glycoprotein & present in exosomes & [39] [55] \\
\hline 28 & inhibitor of thrombopoietin receptor translation & present in exosomes & [39] [56] \\
\hline $34 a$ & suppression of cell proliferation through modulation of the E2F signaling pathway & - & [57] \\
\hline $106 b$ & modulation of TGF $\beta$ signaling in tumors & present in exosomes & [39] [58] \\
\hline 184 & Block of NFAT1 protein expression & present in exosomes & {$[40,43]$} \\
\hline 185 & Inducion of cell cycle arrest in lung cancer cell lines & present in exosomes & {$[40,59]$} \\
\hline 192 & affects cellular proliferation through the p53-miRNA circuit & present in exosomes & [39] [60] \\
\hline 199b & Regulation of protein phosphatase $2 \mathrm{~A}$ inhibitor) in human choriocarcinoma & - & [61] \\
\hline $302 b^{*}$ & regulatory mechanism in tuning stem cell properties & - & [62] \\
\hline $373^{*}$ & Involvement in tumor migration and invasion & present in exosomes & {$[39,46]$} \\
\hline $422 b$ & - & present in exosomes & [40] \\
\hline 431 & - & CNS specific miRNA & {$[47,50]$} \\
\hline 448 & - & - & [63] \\
\hline 455 & - & - & [51] \\
\hline $487 a$ & Role in angiogenesis and cell aging & - & [52] \\
\hline 491 & decreases cell viability by induction of apoptosis & - & [64] \\
\hline $493-3 p$ & - & - & [54] \\
\hline $518^{*}$ & Predicted to be involved in Huntington's disease & - & {$[54,65]$} \\
\hline 522 & - & present in exosomes & [39] \\
\hline $526 a$ & - & present in exosomes & [39] \\
\hline $526 b$ & - & & \\
\hline
\end{tabular}



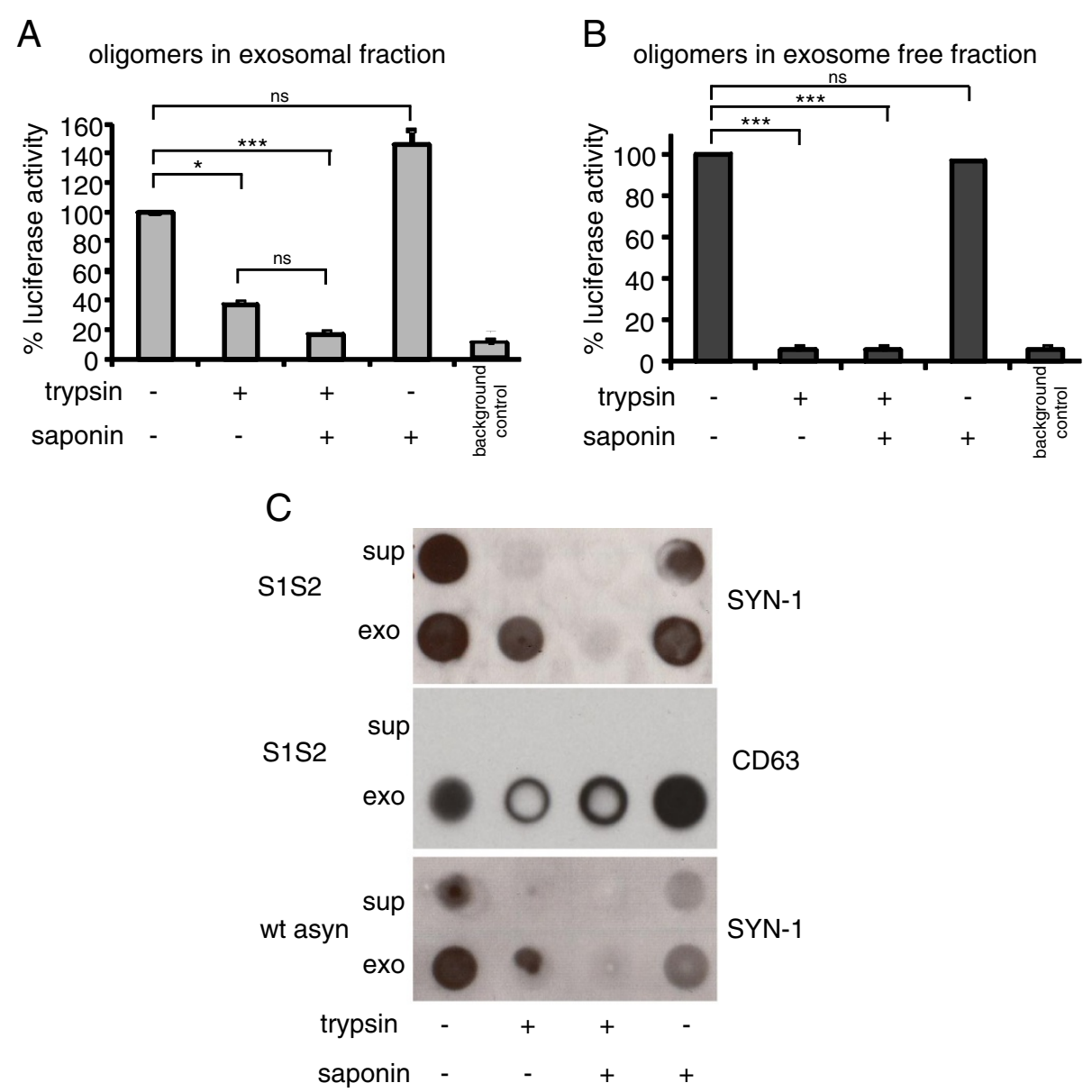

Figure 3 Localization of asyn oligomers within exosomes: (A) Luciferase assay with exosomes derived from human $\mathrm{H} 4$ cells transfected with S1/S2 or $0.1 \%$ saponin/or $0.1 \%$ saponin. (B) Luciferase assay with exosome-free supernatants after asyn oligomer digestion using $0.25 \%$ trysin and/or $0.1 \%$ saponin. (C) Dot blot approach with exosomal fraction (exo) and exosome free supernatant (sup) from H4 cells transfected with S1/ S2 after asyn oligomer digestion using $0.25 \%$ trysin and/or $0.1 \%$ saponin. Probing with syn-1 antibody shows only a complete digestion of asyn oligomers when trypsin and saponin are used concurrently. Signal of exosomal marker CD63 is abolished by addition of solely trypsin.

\section{Exosome-associated asyn oligomers are more prone to} internalization than exosome-free asyn oligomers

It has been reported that recombinant $\alpha$ syn or $\alpha$ syn oligomers can be internalized by cells and result in various cellular effects [18-20,33,67]. Furthermore, we and others have shown that cell produced asyn oligomers can be secreted and taken up by proliferating cells and primary neurons $[17,23]$. To investigate if exosomes are required for the internalization of asyn oligomers, we exposed naive $\mathrm{H} 4$ cells to exosome-associated $\alpha$ syn oligomers or exosome-free supernatant containing asyn oligomers derived from S1/S2 transfected $\mathrm{H} 4$ cells for 3 days. Concurrently, exosomes or exosome-free supernatant from "mock" transfected cells were added to naive $\mathrm{H} 4$ cells. Interestingly, we found that exosome associated asyn oligomers are more prone to being taken up than exosome free asyn oligomers (Figure 4A). To control for the variable amounts of asyn in each exosome or supernatant preparation added to cells, the luciferase signal detected in the recipient cells was normalized back to the initial luciferase counts added to the naïve cells. Data analysed in this way revealed a 2.4 fold increase in uptake of exosomeassociated asyn oligomers compared to exosome-free asyn oligomers (Figure 4B).

Recombinant oligomers as well as physiologically secreted asyn oligomers can cause cell death when applied to culture medium of different cell lines and primary neurons [18-20,23,33,67]. To determine if exosome-associated asyn oligomers confer more cytotoxicity compared to exosome-free $\alpha$ syn oligomers, we applied exosome-enriched fractions or exosome-free fractions derived from S1/S2 or MOCK transfected H4 cells to naïve proliferating $\mathrm{H} 4$ cells and found an increase in Caspase 3/7 activation conferred by exosome associated asyn oligomers (Figure 4C). To ensure the 


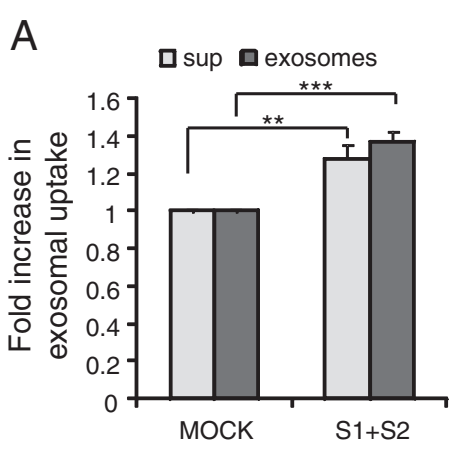

C

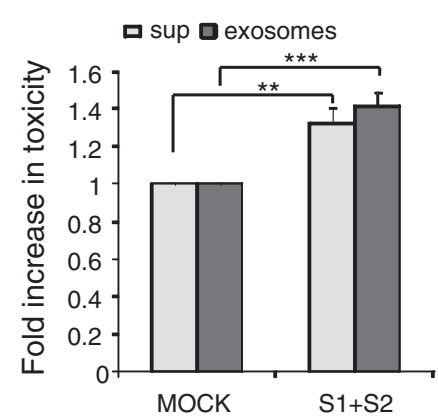

$E$

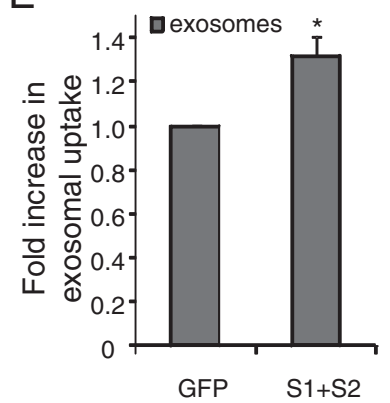

B

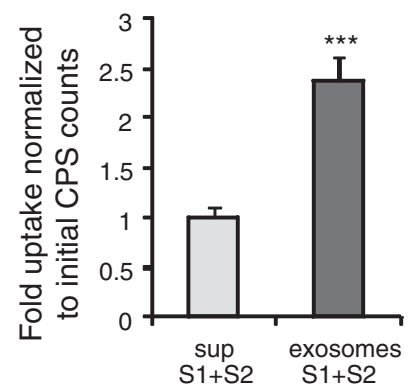

D

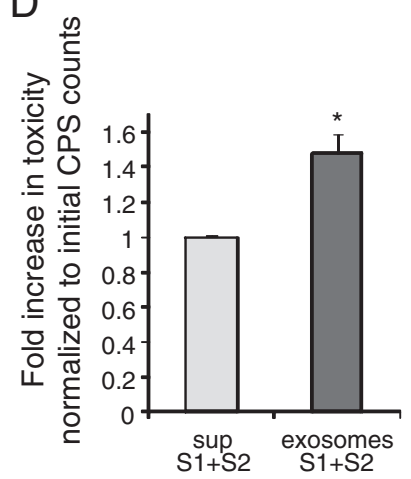

$\mathrm{F}$

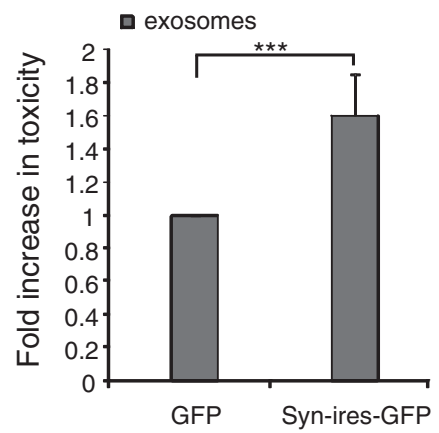

Figure 4 Exosome-associated asyn oligomers are preferentially internalized and more toxic than exosome-free asyn oligomers. (A) Exosomal fractions and exosome-free supernatants (sup) from human $\mathrm{H} 4$ cells transfected with S1/S2 or mock were applied to naive $\mathrm{H} 4$ cells and incubated for 3 days. Uptake of asyn oligomers into recipient cells was measured by luciferase assay. $n=9$, unpaired t test with Welch's correction, ${ }^{* * *} \mathrm{p}<0.001$. (B) Naiive H4 cells treated with exosome-associated S1/S2 oligomers and exosome-free S1/S2 oligomers (sup) were assayed for luciferase activity. Luciferase signal was normalized to the amount of asyn oligomers in the input, $n=9$, unpaired t test with Welch's correction, ${ }^{* * *} p<0.001$. (C) H4 cells treated with exosome-associated asyn fractions conferred greater toxicity on naive $\mathrm{H} 4$ cells than exosomefree asyn ( $\sup n=5$, unpaired t test with Welch's correction, ${ }^{* * *} \mathrm{p}<0.001$ (D) Naïve H4 cells treated with exosome-associated asyn oligomers and exosome free asyn oligomers (sup) were assayed for toxicity. Level of toxicity was normalized to the luciferase activity in each input $n=5$, Mann Whitney test, ${ }^{*} \mathrm{p}<0.05$. (E) Exosomal fractions derived from primary neurons infected with AAV-S1/S2 or AAV-GFP were applied to naive neurons and incubated for 3 days. Uptake of asyn oligomers into recipient neurons was measured performing a luciferase assay on recipient cells. $n=3$, one-sample t-test, ${ }^{*} p<0.05$. (F) Toxicity assay of naïve primary neurons treated with exosome-enriched fractions and exosome-free fractions (sup) derived from either AAV-asyn-ires-GFP or AAV-GFP infected primary neurons. $n=9$, one sample t-test, ${ }^{* *} p<0.001$.

same amount of asyn oligomers in each fraction, the level of Caspase $3 / 7$ activation was normalized to the amount of $\alpha$ syn oligomers prior to the addition to naïve cells. Interestingly, a significant 1.5 -fold increase in Caspase $3 / 7$ activation and resulting apotosis induction from exosome-associated asyn oligomers compared to exosome-free $\alpha$ syn oligomers was detected (Figure 4D).
In accordance with our data for human $\mathrm{H} 4$ cells we confirmed that exosome-associated asyn oligomers could also be taken-up by naive primary neurons (Figure 4E) and induce apoptosis as characterized by an increase in caspase3/7 activity (Figure 4F). Unfortunately, due to high levels of non-specific background bioluminescence from B-27 supplement in our neuronal 
cell culture medium, we were unable to assess the internalization of exosome-free $\alpha$ syn oligomers by primary neurons.

\section{Exosomes need to be intact to be internalized}

Because our data suggest that exosome-associated $\alpha$ syn may be preferentially taken up by neighboring cells, we next asked whether exosomes need to be intact for uptake to occur. To explore this question, we labeled purified exosome-enriched fractions derived from S1/S2 transfected H4 cells with the membrane dye DiD [68]. To delineate the morphology of $\mathrm{H} 4$ cells or primary neurons, we transfected cells with venus-YFP prior to exosome addition resulting in a subpopulation of $\mathrm{H} 4$ cells or primary neurons that could be identified via green fluorescence. As expected when labeled exosomes were exogenously added to $\mathrm{H} 4$ cells or primary neurons in culture, we observed a rapid uptake of labeled exosomes into the cytosol of cells. To investigate whether membrane integrity is important for uptake, exosomes were subjected to sonication which is known to disrupt lipid bilayer integrity [69-71]. Sonication of exosomes prevented the uptake of exosomes by recipient cells
(Figure 5A). These results were confirmed by measuring luciferase activity inside naive cells following incubation with intact or sonicated exosome fractions from syn-luc transfected H4 cells. Where exosomes were sonicated, significantly less luciferase activity was detected inside the naive cells (Figure 5B) although sonication itself had no effect on luciferase activity of exosomal fractions. This uptake was not unique to proliferating cells as we were also able to confirm the uptake of labeled exosomes into primary cortical neurons (Figure 5C). These results demonstrate that intact exosomes promote exosomal uptake.

To confirm that the labeled microvesicles being observed by confocal microscopy were actually exosomes, we immunostained cells with the exosomal marker flotillin and found that the flotillin immunoreactivity colocalized with the DiD labeled exosomes (Figure 5D).

\section{Autophagy regulates asyn secretion}

Exosomes are derived from multivesicular bodies (MVBs), which are endocytic organelles generated by membrane invagination [72-74]. Proteins that are designated for lysosomal degradation are sequestered by

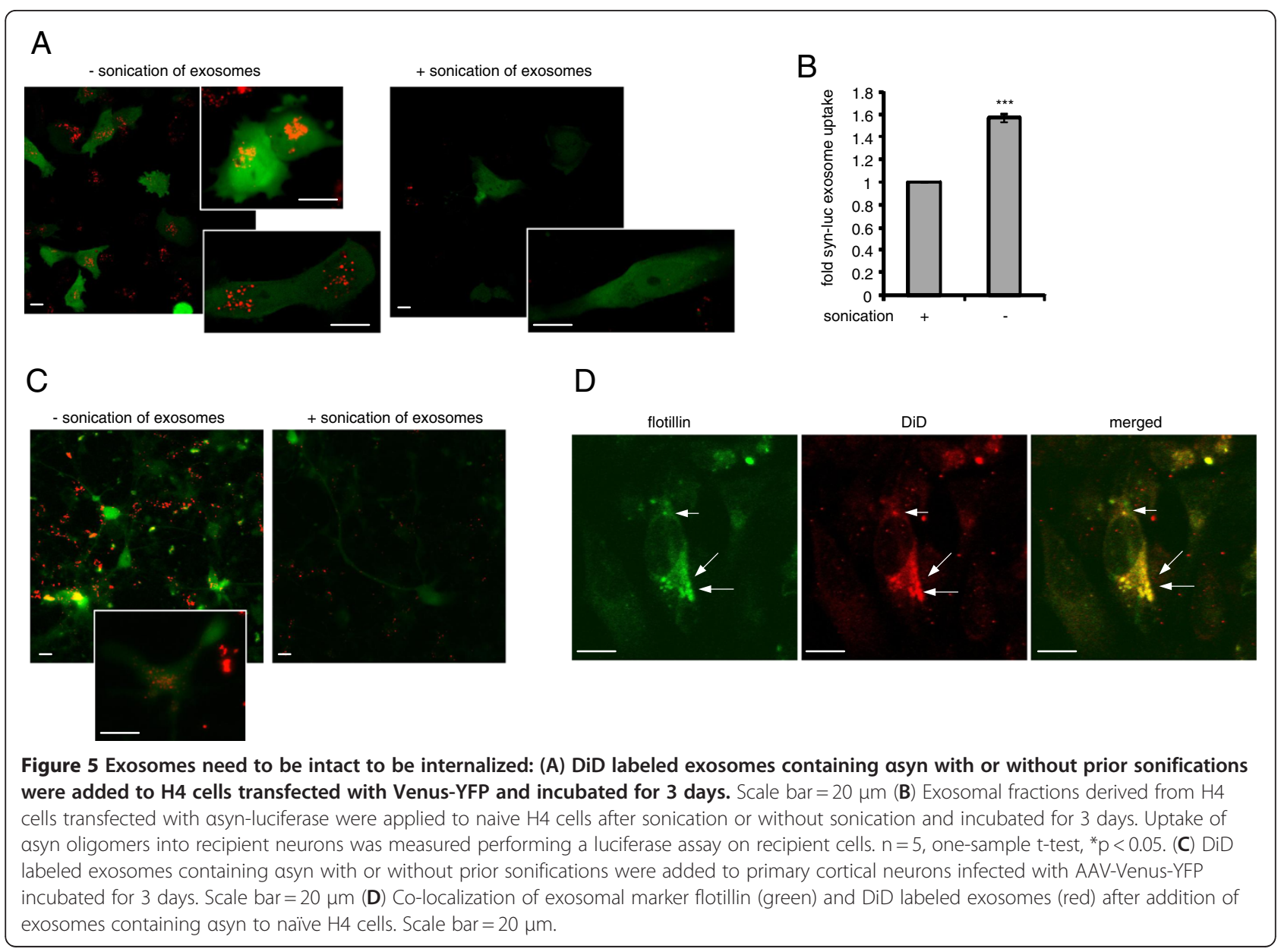


MVBs, however, an alternative destination of MVBs is their exocytic fusion with the plasma membrane leading to the release of intraluminal vesicles (ILVs; i.e., exosome) into the extracellular environment. Interestingly, induction of autophagy can markedly increase the interaction of MVBs and autophagosomes and thereby block exosome secretion [75].

We detected a higher luciferase activity extracellularly (Figure 6A) which may suggest that more oligomers are secreted. However, it's also possible that coelentrazine is more sensitive to extracellular $\alpha$ syn oligomers although it is cell permeable. Nevertheless, given that we detected asyn oligomers in the exosomal fraction of cells and observed that $\alpha$ syn oligomer secretion could be modulated by autophagic activity (Figure 6A) we asked whether autophagy would be a release pathway for exosome-associated $\alpha$ syn oligomers.

Following guidelines for assays monitoring autophagy [76] we measured the levels of LC3.II (ratio with $ß$-actin) and p62 (ratio with $\alpha$-tubulin) in S1/S2 transfected $\mathrm{H} 4$ cells treated with rapamycin, bafilomycin A1 and DMSO. Levels of LC3.II and p62 significantly increased when $\mathrm{H} 4$ cells were treated with bafilomycin A1 compared to DMSO controls, indicating an abundance of autophagosomes due to reduced downstream fusion with lysosomes. The opposite effect was observed when treated with rapamycin (Figure $6 \mathrm{~B}, \mathrm{C}$ ). We speculated that an increased pool of autophagosomes could be the basis for an increased exosomes secretion. Exosomes were isolated from conditioned media of S1/S2 transfected $\mathrm{H} 4$ cells treated with bafilomycin A1, rapamycin or DMSO, and luciferase activity was monitored. A significant increase in luciferase activity in the exosomal fraction from cells that were treated with bafilomycin A1 compared to DMSO control (Figure 6D) was observed which suggests that inhibition of the fusion of the autophagosome with the lysosome by bafilomycin A1 provides an increased pool autophagosomes which enhances exosomal release. Likewise, treatment with the autophagy enhancer rapamycin showed a decreased asyn oligomer signal in the exosomal fraction as measured by luciferase activity compared with DMSO treatment (Figure 6D), suggesting that enhanced lysosomal activity results in effective $\alpha$ syn oligomer degradation and less secretion. We extended these findings to primary neurons and observed an increase in the asyn oligomer signal in the exosomal fraction from neurons treated with bafilomycin A1 and a decrease in the $\alpha$ syn oligomer signal with rapamycin treatment in the exosomal fraction compared to DMSO control (Figure 6E), although these effects did not reach statistical significance $(p=0.17)$, probably due to the fact that the yield of exosomes are significantly less from primary neuronal preparations resulting in barely detectable luciferase and an decrease in the signal/noise ratio. Together, these experiments indicate autophagy can be a specific release pathway for secretion of asyn oligomers.

\section{Discussion}

Multivesicular bodies (MVBs) and their intraluminal vesicles (ILVs) are involved in the sequestration of proteins destined for degradation in lysosomes. However, MVBs can also fuse with the plasma membrane leading to the release of $50-90 \mathrm{~nm}$ ILVs into the extracellular milieu, which are then called exosomes [77,78]. Exosome secretion can therefore be used by cells, including neurons and astrocytes, to clear molecules originally destined for lysosomal degradation [77]. Recently, exosomes have been suggested to play a role in neurodegeneration: Exosomes from prion infected cells have been demonstrated to be efficient initiators of prion propagation in uninfected recipient cells and more importantly, to produce prion disease when inoculated into mice [34,79]. Also the beta-amyloid peptide has been found to be secreted from cells in association with exosomes [80]. Ghidoni et al. suggested that exosomes could be the "Trojan horses" of neurodegeneration; a mechanism underlying the death of cells by shipping toxic agents in exosomes from cell to cell [81]. In our study we identified $\alpha$ syn oligomers to be present in exosomes and found that exosome-associated asyn oligomers are more toxic to neighboring cells than exosome-free $\alpha$ syn oligomers. In contrast to the study of Hasegawa et al. we found that asyn oligomers are present in both the exosomal pellet and the exosome free supernatant from the conditioned media of asyn overexpressing cells whereas Hasegawa et al. recovered $\alpha$ syn mainly from the supernatant fraction [82]. One possible explanation for this discrepancy is the different cellular models and resulting levels of sensitivity. The use of a highly sensitive luciferase protein complementation assay, allows the detection of minimal amounts of protein compared to Western blot analyses.

To our knowledge, this is the first report of asyn oligomers in the exosomal fraction of primary neurons or neuronal cells. Specifically, we have conclusively shown that asyn oligomers can be found outside exosomes, presumably on the outer surface of exosomes. The existence of asyn oligomers outside exosomes has been demonstrated in two ways. First, any external $\alpha$ syn has been digested using trypsin which resulted in a significant decrease in luciferase counts indicative for $\alpha$ syn oligomers. Second, trypsin digestion also led to a dramatic decrease of asyn signal in a Dot blot approach. There are several possible reasons for the existence of $\alpha$ syn oligomers on the external surface of exosomes (Figure 7). First, lipid raft components were found on the membrane surface of secreted exosomes [83]. $\alpha$ Syn has been 


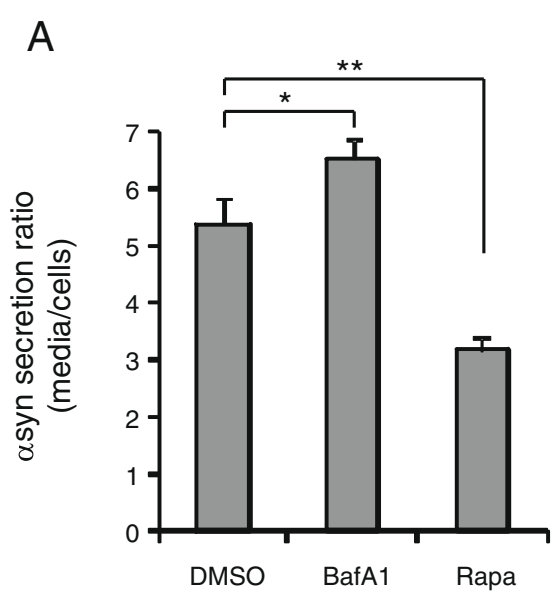

C

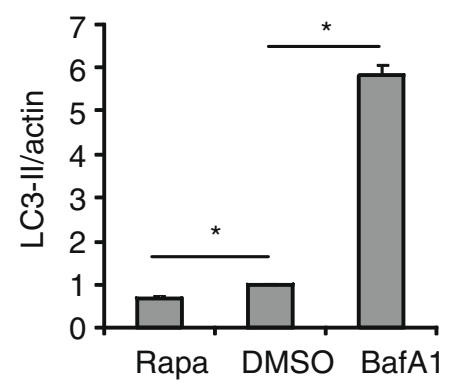

D

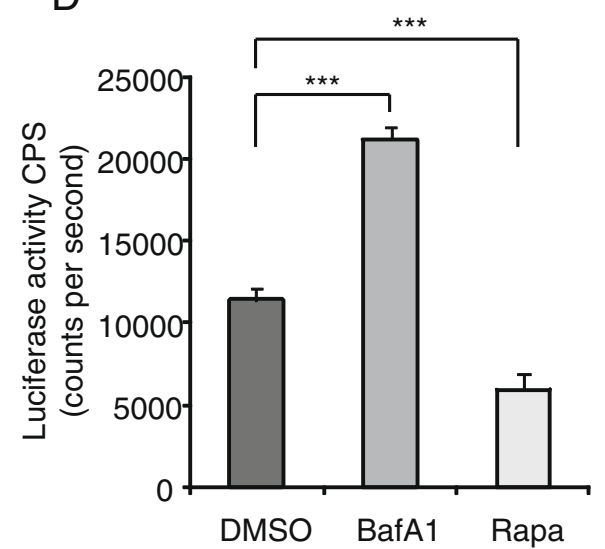

B

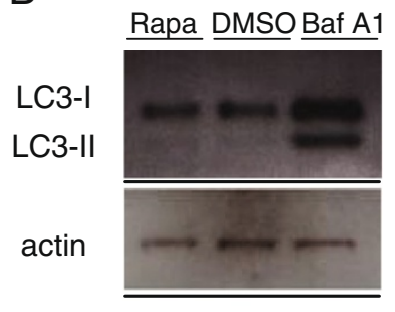

p62

atubulin

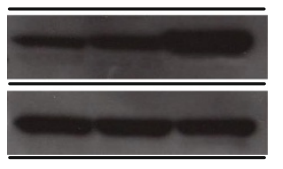

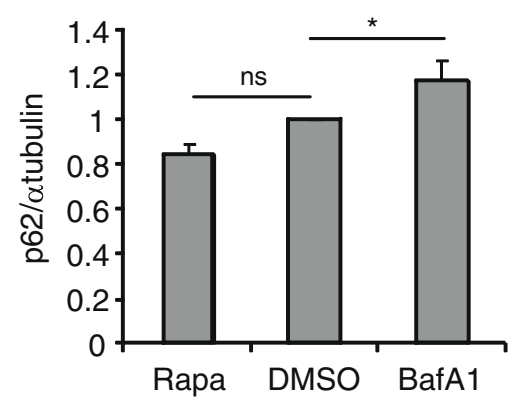

E

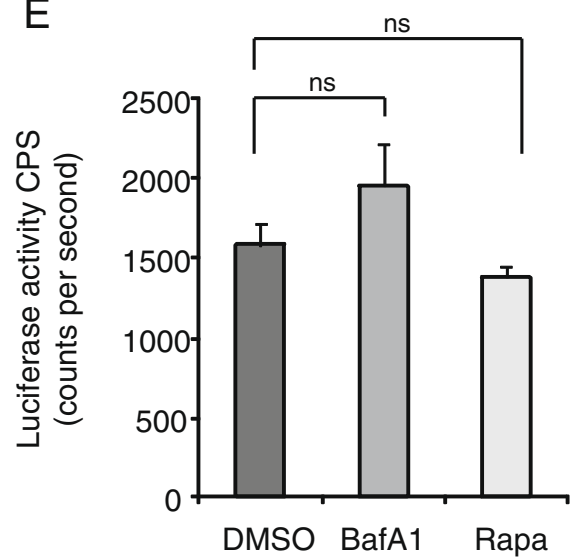

Figure 6 aSyn oligomer secretion is modulated by autophagic activity. (A) Human H4 cells were transfected with asyn complementation pair S1/S2 and treated with DMSO, rapamycin or bafilomycin A1. After $48 \mathrm{~h}$ cells CM was assayed for luciferase activity and a ratio of luciferase activity in media compared to cells was expressed. $n=4$, One way ANOVA, Bonferroni's Multiple Comparison Test, ${ }^{* *} p<0.001$. (B) Immunoblot levels of autophagosome marker LC3.II and macrophagy substrate p62 in H4 cells treated with autophagy inhibitor Bafilomycin A1, autophagy inducer rapamycin or DMSO. (C) Densiometric analysis of immunoblots probed with LC3.II normalized to B-actin[ $n=3$ (Baf A1) $p<0.0001$, t-test; $n=3$ (rapa), $p=0.0021$, t-test ] and p62 normalized a-tubulin [ $n=3$ (Baf A1) $p=0.022$, t-test; $n=3$ (rapa), $p=0.0022$, t-test ] (D) Exosomal fractions from $\mathrm{H} 4$ cells transfected with S1/S2 and treated with DMSO, rapamycin or bafilomycin A1 were assayed for luciferase activity. $n=4$, One way ANOVA, Bonferroni's Multiple Comparison Test, ${ }^{* *} \mathrm{p}<0.001$ (E) Exosomal fractions from primary neurons infected with AAV-S1/S2 and treated with DMSO, rapamycin or bafilomycin A1 were assayed for luciferase activity. $n=4$, One way ANOVA, Bonferroni's Multiple Comparison Test, $\mathrm{p}=0.17$, ns = non-significant. 


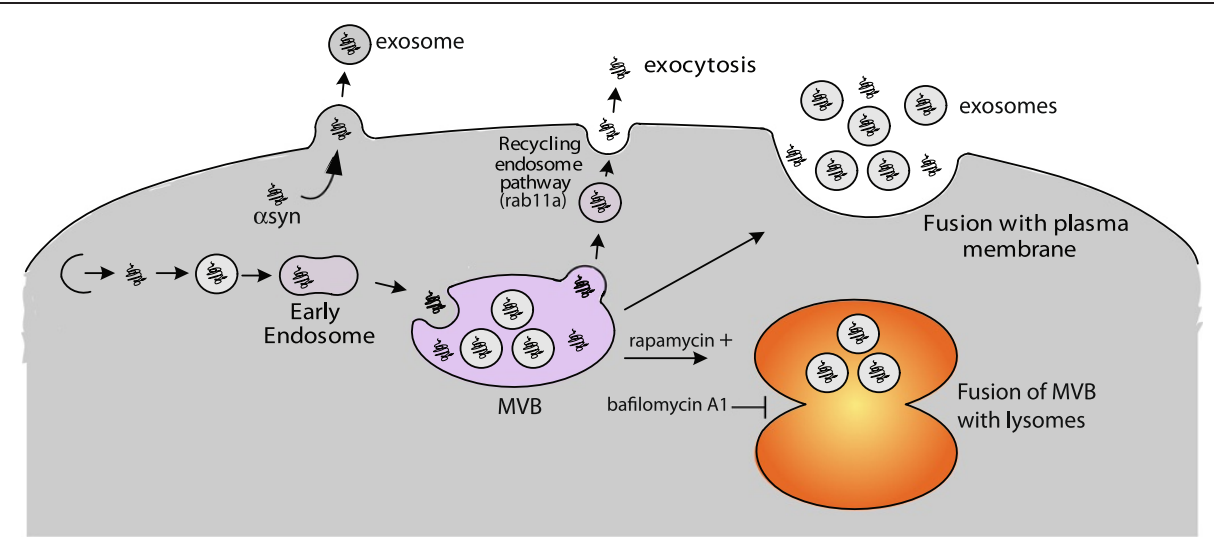

Figure 7 Schematic presentation of endosomal pathways and possible asyn secretory pathways. Membrane associated cargo proteins including asyn or cytosolic asyn are translocated to early endosomes. Invagination and final scission of the endosomal membrane contribute to MVB formation. MVB direct either for lysosomal degradation by fusion from the autophagosome with the lysosome or for secretion as exosomes by exocytic fusion with the plasma membrane. Under physiological conditions asyn in the early endosome may be transferred to MVB and then targeted for lysosomal degradation. Alternatively, asyn might be secreted into the extracellular milieu through the rab11a dependent recycling endosome (free asyn) and MVB-exosome pathway (free and exosome associated asyn). Exosomes can also enter in the extracellular interspace by outward budding of the plasma membrane.

shown to interact with lipid rafts and artificial membranes $[84,85]$ and a recent report demonstrates that asyn can penetrate in the outer leaflet of a bilayer [86].

We also found asyn present in the inside of exosomes. Cytosolic proteins like asyn can end up in ILVs because plasma membrane invagination occurs during endocytosis and results in the formation of early endosomes encapsulating a significant amount of cytosol (Figure 7). Endosomal membranes further invaginate to form ILVs, which give endosomes their multi-vesicular appearance. When MVBs fuse with the plasma membrane they can then be released as exosomes containing the encapsulated cytosolic proteins like $\alpha$ syn [87]. Why asyn oligomers are encapsulated in MVB's and released as exosomes is not understood. Possible explanations include first, that $\alpha$ syn oligomers in exosomes could represent the species that are most harmful to cells and is thus targeted for release. Second, Fang et al. have proposed that proteins which exhibit higher order oligomerization and are associated with the plasma membrane, are preferentially sorted into exosomes [88]. A third explanation for the presence of $\alpha$ syn oligomers in exosomes could be that exosomes provide an environment that is favorable for the oligomerization process. Indeed, lipid-mediated oligomerization seems to be important in amyloid formation and polyunsaturated fatty acids have been shown to trigger multimerization of recombinant $\alpha$ syn [89].

We also found asyn oligomers in the exosome-free fraction. One explanation for the presence of exosomefree asyn oligomers could be that the the exosomal membrane undergoes extracellular degradation via proteases or lipases that would lead to the release of proteins from the exosomal lumen to the extracellular environment during the fractionation process [90,91]. Another explanation could be that $\alpha$ syn oligomers might become unstable and lose their affinity for lipid membranes after being released from the cell, due to changes in the $\mathrm{pH}$ value or ionic strength in the extracellular space. In fact, only a small fraction of Abeta peptide is found associated with exosomes [80], which supports our observations. A third explanation for the secretion of soluble, nonexosomal asyn oligomers could be that there is an exosome-independent pathway of asyn secretion (Figure 7) maybe through the Rab11a-dependent recycling endosomal pathway [82,92], however, further in depth studies will be needed to determine if this is the case. Supporting evidence for the presence of asyn in the exosomal fraction also comes from the recent studies of Emmanouilidou et al. and Alvarez-Erviti [23,24]. Taken together with the previously published studies, our findings support the "Trojan horse" hypothesis [81].

Our data make a case for exosomal transfer of $\alpha$ syn from cell to cell and could represent a key mechanism in the spread of asyn aggregates between neurons in the brain. Indeed, exosomes are biologically active vesicles that are thought to be important for intercellular communication [93,94]. Valadi et al. recently reported that exosomes also contain both mRNA and microRNA, which can be delivered to neighboring cells and be functional in the recipient cell [40]. Exosomes can interact with recipient cells in different ways, including endocytosis, fusion with the plasma membrane, receptorligand-binding or attachment [78,95-97].

Critical to our understanding of the toxic effects of secreted asyn oligomers on neighboring cells is the 
identification of the toxic species. Our data support the possibility that both exosome-associated $\alpha$ syn oligomers and exosome-free $\alpha$ syn oligomers can confer toxicity on neighboring cells. We found that exosome-associated asyn oligomers are more likely to be taken up by neighboring cells, although we also observe the uptake of free asyn oligomers. The same holds true in terms of toxicity: exosome-associated $\alpha$ syn oligomers are more toxic to neighboring cells compared to free $\alpha$ syn oligomers. It is tempting to speculate that the more $\alpha$ syn oligomers that are taken up by recipient cells, the greater the toxicity. However, it remains to be determined whether asyn oligomers exert their toxic effects after being taken up by recipient cells by impacting cellular homeostasis $[98,99]$ or if extracellular asyn oligomers exert their effect at the cell membrane.

Autophagy can function as a protective mechanism in cells and is particularly crucial in the aging brain and in neurodegeneration where aggregated proteins accumulate [100]. It is now thought that $\alpha$ syn can be degraded by either the proteasome or by autophagy and both macroautophagy and CMA have been reported to contribute to asyn degradation [101-104]. In this study, we demonstrate that secretion of asyn oligomers is increased when lysosomal activity is blocked by Baf A1. Baf A1 inhibits the fusion of the autophagosome with the lysosome by inhibiting vacuolar type $\mathrm{H}(+)$-ATPase [105], thereby inhibiting lysosomal activity. We speculate that by blocking the major degradation pathway for $\alpha$ syn oligomers, the cells use secretion as an alternative pathway to eliminate harmful $\alpha$ syn oligomeric species. By contrast, we did not detect a significant effect of proteasomal inhibition with MG132 on the secretion of asyn oligomers. These results support a hypothesis where autophagy is the major route for degradation of asyn oligomers which are then targeted to the plasma membrane to be cleared by secretion as an alternative route upon failure of this pathway. This assumption is also supported by the fact that rapamycin decreased $\alpha$ syn secretion by enhancing autophagy and thereby triggering intracellular degradation of asyn oligomers. Our results are also in line with the recent work from Emmanouilidiou et al., who did not observe an effect of proteasome inhibitor on levels of extracellular $\alpha$ syn, but found a profound increase in the levels of secreted asyn when the lysosomal pathway was blocked by methylamine [23]. Our study specifically investigates the regulation of secretion of oligomeric asyn upon autophagy inhibition or activation, supporting and significantly augmenting the published study. The fact that we observed more asyn oligomers in the exosomal fraction after inhibition with BafA1 raises the possibility that $\alpha$ syn oligomer containing vesicles (presumably ILVs) originally destined for lysosomal degradation, were re-directed to the plasma membrane and released as exosomes. This hypothesis requires an interaction between exosomal and autophagic pathways. Indeed, a recent study by Fader et al. demonstrated that induction of autophagy markedly increased the interaction of MVBs and autophagosomes and concurrently blocked exosome secretion, suggesting that MVBs are directed to the autophagic pathway with a consequent inhibition in exosome release [75].

In conclusion, we demonstrate that $\alpha$ syn oligomers can be found in different extracellular fractions in association with exosomes or as exosome-free oligomers. $\alpha$ Syn oligomers associated with exosomes are more toxic to recipient cells compared to free $\alpha$ syn oligomers. The toxic mechanisms of asyn oligomers spreading from cell to cell described here in cell culture could resemble events explaining the spread of $\alpha$ syn pathology that has been observed in human post-mortem brains [8]. Additional studies are needed to verify exosome-associated asyn oligomers and exosomal release in the brains of PD patients. Preventing the early events in exosomal release and uptake by inducing autophagy might be a novel approach for the development of effective drugs for the treatment of PD and other synucleinopathies.

\section{Conclusions}

These data demonstrate that oligomeric forms of $\alpha$ syn can be found in multiple extracellular fractions: associated with exosomes and free. Exosome-associated $\alpha$ syn oligomers are more likely to be taken up by recipient cells and can induce more toxicity compared to free asyn oligomers. In addition, we determined $\alpha$ syn oligomers oligomers to be present both on the outside of exosomes as well as inside of exosomes. Notably, the pathway of secretion of asyn oligomers is strongly influenced by autophagic activity. Preventing the early events in $\alpha$ syn exosomal release and uptake by inducing autophagy may be a novel approach to halt disease spreading in PD and other synucleinopathies.

\section{Methods}

\section{Plasmid generation}

Fusion constructs $\alpha$ syn-hGLuc1 (S1), $\alpha$ syn-hGLuc2 (S2)

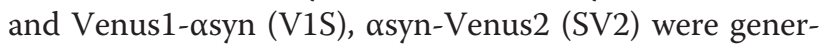
ated by subcloning $\alpha$ syn into Not1/Cla1 sites of humanized Gaussia Luciferase and VenusYFP constructs provided by Dr. Stephen Michnick of University of Montreal $[25,28]$.

\section{$A A V$ vectors construction and production}

The viral vectors rAAV-CBA-WPRE, rAAV-CBA-IRESEGFP and rAAV-CBA-SYNUCLEIN-IRES-EGFP were described previously [29]. rAAV-CBA-SYNUCLEINLUC1-WPRE (AAV-S1) and rAAV-CBA-SYNUCLEINLUC2-WPRE (AAV-S2) were constructed as follows: 
asyn -hGLuc1 (S1) and asyn -hGLuc2 (S2) were subcloned into Not1/Nhe1 sites of AAV-CBA-WPRE vector. rAAV-CBA- VENUS1-SYNUCLEIN-WPRE (AAV-V1S) and rAAV-CBA-SYNUCLEIN-VENUS2-WPRE (AAVSV2) were constructed as follows: the fragments Venus1-Synuclein and Synuclein-Venus2 was inserted into the EcoRV and NheI sites of the pAAV-CBA-WPRE vector. Recombinant adeno-associated type $2 / 8$ was generated by tripartite transfection (AAV-rep/cap expression plasmid, adenovirus miniplasmid and AAV vector plasmid) into 293A cells and purified by iodixanol gradient followed by $\mathrm{Q}$ sepharose column chromatography (Harvard Gene Therapy Initiative, Harvard Medical School). The purified virus was dialyzed against PBS, concentrated by Amicon spin column, and tittered by dot blot hybridization. Final titers for virus were for AAV-S1 $1.5 \mathrm{E} 13 \mathrm{gc} / \mathrm{ml}$, AAV-S2 $1.3 \mathrm{E} 13 \mathrm{gc} / \mathrm{ml}, \mathrm{V} 1 \mathrm{~S}$ $8.3 \mathrm{E} 12 \mathrm{gc} / \mathrm{ml}$ and SV2 8.7E12 $\mathrm{gc} / \mathrm{ml}$.

\section{Human asynuclein ELISA}

Alpha synuclein concentration was quantified using human asyn specific ELISA (\#KHB0061, Invitrogen, Carlsbad, CA, USA) according to the manufacturer's instructions. Absorbance is read at $450 \mathrm{~nm}$. The absorbance is directly proportional to the concentration of $\alpha$ syn present in the original specimen. $\alpha$ Syn concentration was determined by plotting sample absorbances against standards using Graph Pad Prism fitting software (four parameter algorithm).

\section{Cell culture and transfections}

Unless otherwise stated, human $\mathrm{H} 4$ neuroglioma cells (HTB-148 - ATCC, Manassas, VA, USA) were maintained in OPTI-MEM medium supplemented with $10 \%$ fetal bovine serum (both from Invitrogen) and incubated at $37^{\circ} \mathrm{C}$. Cells were plated 24 hours prior to transfection, growing to $80-90 \%$ confluency prior to transfection. Transfection was performed using Superfect (Qiagen, Chatsworth, CA, USA) using equimolar ratios of plasmids according to the manufacturer's instructions. Conditioned media was collected 48 hours post-transfection and centrifuged for $5 \mathrm{~min}$ at $3000 \mathrm{~g}$ to eliminate floating cells before being used.

\section{Gaussia luciferase protein-fragment complementation assay}

Fusion constructs $\alpha$ syn hGLuc1 (S1) and $\alpha$ syn -hGLuc2 (S2) were generated as described previously [25]. S1 and S2 were transfected into $\mathrm{H} 4$ cells in a 96-well plate format as described above. $48 \mathrm{~h}$ after transfection, culture media was transferred to a new 96 well plate (Costar, Corning, NY, USA). Cells were washed with PBS and replaced with serum- and phenol-red free media. Luciferase activity from protein complementation was measured for conditioned media and live cells in an automated plate reader at $480 \mathrm{~nm}$ following the injection of the cell permeable substrate, coelenterazine $(20 \mu \mathrm{M})$ (Prolume Ltd, Pinetop, AZ) with a signal integration time of 2 seconds.

\section{Primary cortical cell culture}

Primary cortical neurons were prepared from cerebral cortices of E14-16 mouse embryos. Cortices were dissected from embryonic brain and the meninges were removed. Cortices were dissociated by titruation at RT and cells were resuspended in Neurobasal (NB) (Gibco) medium supplemented with $10 \%$ fetal bovine serum, $2 \mathrm{mM}$ Glutamax, $100 \mathrm{U} / \mathrm{mL}$ penicillin, and $100 \mu \mathrm{g} / \mathrm{mL}$ streptomycin and plated at a density of $3.84 \times 10^{4}$ cells/ well on 96w plates (Corning, NY, USA), $60 \mathrm{~mm}$ dishes at a density of $3.6 \times 10^{6}$ cells/dish (Costar, Corning, NY, USA) coated with $20 \mu \mathrm{g} / \mathrm{mL}$ poly-D-lysine(SigmaAldrich, St. Louis, MO, USA). After $2 \mathrm{~h}$ medium was changed into NB/B-27 [NB medium containing 2\% (v/v) B-27 supplement], $100 \mathrm{U} / \mathrm{mL}$ penicillin, $100 \mu \mathrm{g} / \mathrm{mL}$ streptomycin, and $2 \mathrm{mM} / \mathrm{L}$ glutamine. Cells were maintained at $37^{\circ} \mathrm{C}$ in $5 \% \mathrm{CO}_{2}$ in a humidified incubator. Medium was changed every third day. Neurons were grown for 4-5 days in vitro (DIV) before infected with AAV8-S1/AAV8-S2, AAV8-V1S/AAV8-SV2, AAV8-synires-GFP or AAV8-GFP. Infections were carried out as followed: $6 \mu \mathrm{l} \mathrm{rAAV} 2 / 8$ expressing eGFP $(1.3 \mathrm{E} 13 \mathrm{gc} / \mathrm{ml})$ per $60 \mathrm{~mm}$ dish, $6 \mu \mathrm{l} \mathrm{rAAV} 2 / 8$ expressing $\alpha \mathrm{syn}(\mathrm{wt})$-iresGFP $(1.1 \mathrm{E} 13 \mathrm{gc} / \mathrm{ml})$ per $60 \mathrm{~mm}$ dish and $3 \mu \mathrm{lAAV} 2 / 8$ expressing V1S $(8.3 \mathrm{E} 12 \mathrm{gc} / \mathrm{ml})$ together with $3 \mu \mathrm{rAAV} 2 /$ 8 expressing SV2 $(8.7 \mathrm{E} 12 \mathrm{gc} / \mathrm{ml})$ per $60 \mathrm{~mm}$ dish, as well as $3 \mu \mathrm{l} \mathrm{rAAV} 2 / 8$ expressing $\mathrm{S} 1(1.5 \mathrm{E} 13 \mathrm{gc} / \mathrm{ml})$ together with $3 \mu \mathrm{l}$ rAAV2/8 expressing $\mathrm{S} 2(1.3 \mathrm{E} 13 \mathrm{gc} / \mathrm{ml})$ per $60 \mathrm{~mm}$ dish.

\section{Exosome isolation}

Exosomes from Human H4 cells and primary neurons were prepared as described earlier [34,35] with minor modifications. Briefly, conditioned medium was collected and spun for $5 \mathrm{~min}$ at 500xg to remove floating cells. The supernatants were then sequentially centrifuged at $300 \mathrm{xg}(10 \mathrm{~min})$ and $2 \mathrm{x} 200 \mathrm{xg}(10 \mathrm{~min})$ at $4{ }^{\circ} \mathrm{C}$ each. Then supernatants were filtered through a $0.45 \mu \mathrm{m}$ (Whatmann, Florham Park, NJ) and then $0.22 \mu \mathrm{m}$ (Millipore, Carrigtowhill, Cork, Ireland) filter, and centrifuged for 30 minutes at $10,000 \mathrm{xg}(2 \mathrm{X})$ at $4^{\circ} \mathrm{C}$. After ultracentrifugation at $100,000 \mathrm{xg}$ for $70 \mathrm{~min}$ at $4^{\circ} \mathrm{C}$, exosomal pellet was then resuspended in $1 \mathrm{xPBS}$ for Western Blotting, electron microscopy or luciferase assay or resuspended culture medium for cell treatments.

Exosome depleted medium was prepared as described above, except after ultracentrifigation at 100,000xg for 
$70 \mathrm{~min}$ at $4^{\circ} \mathrm{C}$, exosome free supernatant was filtered through a $0.22 \mu \mathrm{m}$ filter before used in cell culture.

\section{Digestion of exosomes}

Exosome associated or exosome free asyn oligomers were digested by addition of $0.25 \%$ trypsin (Invitrogen, Carlsbad, CA, USA) and/or $0.1 \%$ saponin and incubated for $20 \mathrm{~min}$ at $37^{\circ} \mathrm{C}$. After complete digestion samples were analyzed in luciferase assay or Dot blot approach.

\section{Labeling of exosomes}

The exosomes were labelled using DiD (Biotium, Hayward, CA USA) according to manufacturer's instructions in a 1:200 dilution. Briefly, after the final spin in exosome purification exosomal pellet was resuspended in $1 \mathrm{ml} \mathrm{DiD}$ solution and incubated for 5 minutes. After ultracentrifugation at $100,000 \mathrm{xg}$ for $70 \mathrm{~min}$ at $4^{\circ} \mathrm{C}$ the exosomal pellet was washed in $1 \mathrm{xPBS}$ centrifuged again for $90 \mathrm{~min}$ at $150000 \mathrm{~g}$ to remove free dye. Then the pellet is resuspended finally as exosome fraction.

\section{Dot blot}

Exosomes or exosome free supernatant was collected as described previously. 100ul of each condition was applied to nitrocellulose membrane (pore size $0.22 \mathrm{um}$, Whatman Protran,Sanford, ME, USA) placed in a Dot blot apparatus (Schleicher \& Schuell Minifold-I Dot-Blot System, Whatman, Sanford, ME, USA, ) and incubated at RT for $1 \mathrm{~h}$. Samples were filtered through the membrane by gentle vacuum and developed using conditions as described previously (21). Briefly, the membrane was blocked with $10 \%$ non-fat dried milk in Tris-buffered saline (TBS, Sigma-Aldrich, St. Louis, MO, USA) containing $0.01 \%$ Tween 20 (TBS-T), at room temperature for $1 \mathrm{~h}$. After three washes with TBS-T, the membrane was incubated with anti- Syn-1 antibody (1:1000; BD transduction, Franklin Lakes, NJ, USA) or monoclonal antiCD63 antibody (1:500, BD Transduction) overnight at 4 $\mathrm{C}$ with gentle agitation. The membranes were then washed three times for $5 \mathrm{~min}$ with TBS-T, incubated with horseradish peroxidase conjugated anti mouse IgG (Jackson Immuno Research Laboratories, Baltimore, PA, USA) diluted 1:2000 in 5\% non-fat dried milk in Trisbuffered saline (TBS) containing $0.01 \%$ Tween 20 (TBS$\mathrm{T})$ and incubated for 1 hour at room temperature. The blots were washed three times with TBS-T and developed with Pierce ECL chemiluminescence kit from Thermo Scientific (Rockford, IL, USA).

\section{Pharmacological treatments in vitro}

H4 cells were plated into 96 well plates or $60 \mathrm{~mm}$ dishes (Costar, Corning, NY, USA) and transfected as described above. Transfection mix was incubated for $2 \mathrm{~h}$ according to manufacturer's protocol, then media was replaced by fresh culture media containing $0.4 \mu \mathrm{g} / \mathrm{ml}$ rapamycin (Sigma Aldrich, St. Louis, MO) or DMSO (Sigma Aldrich, St. Louis, MO) and incubated for 48 h. 200nM Bafilomycin A1 (Merck KG, Darmstadt, Germany) was added to the culture medium $20 \mathrm{~h}$ before harvesting the medium. Conditioned medium was collected for aluciferase assay or exosomal isolations. To ensure that pharmacological treatments result in a true increase in the secretion ratio of asyn oligomers and not simply a matter of more available asyn oligomers in the cytoplasm, we calculated the ratio of secreted asyn oligomers in the conditioned medium to intracellular asyn oligomers.

Primary neurons were plated into $60 \mathrm{~mm}$ dishes (Costar, Corning, NY, USA) and infected as described above. DMSO and $0.1 \mu \mathrm{g} / \mathrm{ml}$ rapamycin were added to the culture medium right after infection, whereas 100nM bafilomycin A1 was added after 3 days expression and incubated for $20 \mathrm{~h}$. Conditioned medium was then collected to perform exosomal isolations.

\section{Exosomal uptake experiments}

Conditioned media from naïve $\mathrm{H} 4$ cells or naïve primary neurons was replaced by exosome containing culture media. After 3-4 days incubation cells were washed twice with $1 \mathrm{xPBS}$ and then assayed for luciferase activity.

\section{Toxicity assay}

Toxicity was analyzed 3-4 days after exosome application by measuring the activity of Caspases 3 and 7 using a fluorometric substrate Z-DEVD-Rhodamine 110 (ApoONE homogeneous Caspase-3/7 assay \#G7790, Promega, Madison, WI) according to the manufacturer's protocol.

\section{Western blotting}

Primary cortical neurons were scraped from $60 \mathrm{~mm}$ dishes and washed by centrifugation and resuspension in cold PBS. The cells were resuspended in 1x PBS containing protease inhibitors (protease inhibitor cocktail tablet 1 tablet/10 mL (Roche Diagnostics) sheared by passing through a 27 -gauge $1 \mathrm{ml}$ syringe $4-6$ times and centrifuged for $5 \mathrm{~min}$ at 13,000 g. Lysates or exosomal samples were resolved by electrophoresis on a 4-12 \% Bis-Tris gradient gel (NuPAGE Novex Bis-Tris Gel, Invitrogen, Carlsbad, CA, USA) according to manufacturer's instructions using NuPAGE MOPS buffer. After transfer to nitrocellulose membrane (Protran, Schleicher and Schuell, Whatman GmbH, Dassel, Germany) membranes were blocked in either $5 \%$ milk inTBS-T or LiCor blocking buffer (LI-COR,Lincoln, NE, USA) for 1 hour at room temperature. Membranes were then incubated with primary antibodies (mouse anti-Alix, 
1:500, BD Transduction; mouse anti-flotillin: monoclonal, 1:500, BD Transduction) overnight at 4 C. After three 5-10 min TBS-T washes, membranes were incubated at room temperature for 1 hour with either IRlabeled secondary antibodies (IR800 goat anti-mouse, 1:2000, Rockland Immunochemicals, PA,USA) or HRPconjugated secondary antibodies (1:2000). After three 5- 10 min TBS-T washes, immunoblots were analyzed using either the Odyssey Infrared imaging system (LiCor, Lincoln, NE,USA) or the ECL chemiluminescent detection system (Amhersham/GE HealthCare, Buckinghamshire, UK).

\section{Cell imaging and immunofluorescence staining}

All images were acquired using a 20x Plan Apochromat lens (Carl Zeiss), 25x APO-Plan NEOFLU lens (Carl Zeiss) or Zeiss 63x 1.2 NA C-APO-Plan NEOFLU water immersion lens (Carl Zeiss), mounted on the microscope described before. $\mathrm{H} 4$ cells or cortical neurons were washed three times with phosphate-buffered saline (PBS) following $30 \mathrm{~min}$ incubation in a fixation solution containing 4\% paraformaldehyde in PBS. After washing, the cells were permeabilized and unspecific binding sites were blocked using 0.05\% Saponin and 1\% bovine serum albumin in PBS followed by another washing step. The primary rabbit antibody against flotillin (1:500, BD Transduction) was added for $1 \mathrm{~h}$ at RT, followed by another washing step and incubation with the secondary antibody (anti-mouse antibody labeled with Alexa-Fluor 488; Invitrogen) for $1 \mathrm{~h}$ at $\mathrm{RT}$.

\section{Electron microscopy}

An exosome pellet from either human $\mathrm{H} 4$ cells or primary neurons was prepared by centrifugation as described above and then resuspended in $20 \mu \mathrm{l}$ of cold Karnovsky's EM fixative (2\% formaldehyde and 2.5\% glutaraldehyde in 0.1 M Sodium Cacodylate buffer, $\mathrm{pH}$ 7.4.). Ultrathin sections from LR white embedded samples were picked up from the knife with a loop, dipped in a 2:1 mixture of $2.3 \mathrm{M}$ sucrose and $2 \%$ methylcellulose, and adsorbed to the surface of a formvar/carbon coated copper grid. Grids are placed on $2 \%$ gelatin in a small petri dish and stored in the fridge until immunogold labeling. This was accomplished by washing grids in PBS and then either treating with CD63 antibody (BD Transduction) followed by $10 \mathrm{~nm}$ gold labelled secondary antibodies (Sigma Aldrich, St. Louis, MO) or processing without immunolabelling. These exosome containing grids were then post-fixed with $2.5 \%$ glutaraldehyde, washed and contrasted with $2 \%$ methyl cellulose and $3 \%$ aqueous uranyl acetate. Samples were examined and photographed with a JEOL 1200EX electron microscope.

\section{microRNA profiling and data analysis}

For nucleic acid analysis, the entire exosome pellet is gently resuspended in $20 \mu \mathrm{l}$ of $1 x \mathrm{PBS}$. Any cellular/ ribosomal RNAs that may exist in the extra-exosomal solution (53) are eliminated by adding $8 \mu \mathrm{g}$ of RNAse T1/A (Fermentas) to the 20ul preparation and incubating for 10 minutes at $37^{\circ} \mathrm{C}$. Four hundred units of SuperRase-in RNAse (Ambion) inhibitor are then added to inactivate the RNAses and the sample is held at $25^{\circ} \mathrm{C}$ for 10 minutes. The entire mixture is then dissolved in $60 \mu \mathrm{l}$ of miRNA extraction buffer (Arcturus), incubated at $42^{\circ} \mathrm{C}$ for 30 minutes, and stored at $-80^{\circ} \mathrm{C}$ prior further processing. In order to generate amplified sense RNA from small quantities $(<1 \mathrm{ng})$ of purified miRNAs, we used the NCode miRNA Amplification System (Invitrogen) according to the manufacturer's instructions. miRNA expression profiles were generated by adding $250 \mathrm{ng}$ of this amplified miRNA to the FlexMiR miRNA assay from Luminex Corporation (Austin, Texas) and running on a Luminex FlexMAP 3D system according to the manufacturer's instructions.

\section{Statistical analysis}

Statistical analyses were carried out using the program GraphPad Prism, Version 4.0. Values in the figures are expressed as means +/- SEM.

\section{Additional file 1}

Additional file 1: Schematic representation of the asyn protein fragment complementation constructs. (A) Nonbioluminescent halves of humanized gaussia luciferase are fused to asyn monomers (B) Non fluorescent halves of Venus-YFP are fused to asyn monomers.

\section{Abbreviations}

PD: Parkinson's disease; asyn: Alpha synuclein; CM: Conditioned media; V1S: Venus YFP fused to the N-terminus of asyn; SV2: C-terminal half of Venus YFP fused to the C-terminus of asyn; S1: asyn fused to amino-terminal fragment of Gaussia princeps luciferase; S2: asyn fused to carboxy-terminal fragment of Gaussia princeps luciferase; MVBs: Multivesicular bodies; CSF: Cerebrospinal fluid.

\section{Competing interests}

The author declares that they have no competing interests.

\section{Authors' contributions}

KMD, LRK, WPR, OCG, ARW, LZ and CRV performed the experiments. KMD and PJM and analyzed the results, designed the study, and wrote the manuscript. All authors read and approved the final manuscript.

\section{Acknowledgements}

This work was supported by NIH NS063963 to PJM. We thank Harvard Medical School EM core for electron microscopy assistance.

\section{Author details}

'MassGeneral Institute for Neurodegenerative Disease, Department of Neurology, Massachusetts General Hospital, Charlestown, MA, USA. ${ }^{2}$ Advanced Tissue Resource Center, Harvard NeuroDiscovery Center, Harvard Medical School, Boston, MA, USA. ${ }^{3}$ Present address: Neurology Department University of Ulm, UIm, Germany. ${ }^{4}$ Present address: Department of Neuroscience, Mayo Clinic, 4500 San Pablo Rd, Jacksonville, FL 32224, USA. 
Received: 25 April 2012 Accepted: 14 August 2012

Published: 24 August 2012

\section{References}

1. Goedert M: Alpha-synuclein and neurodegenerative diseases. Nat Rev Neurosci 2001, 2(7):492-501.

2. Chartier-Harlin MC, Kachergus J, Roumier C, Mouroux V, Douay X, Lincoln S, Levecque C, Larvor L, Andrieux J, Hulihan M, et al: Alpha-synuclein locus duplication as a cause of familial Parkinson's disease. Lancet 2004, 364(9440):1167-1169.

3. Singleton AB, Farrer M, Johnson J, Singleton A, Hague S, Kachergus J, Hulihan M, Peuralinna T, Dutra A, Nussbaum R, et al: alpha-Synuclein locus triplication causes Parkinson's disease. Science 2003, 302(5646):841.

4. Krüger R, Kuhn W, Müller T, Woitalla D, Graeber M, Kosel S, Przuntek H, Epplen JT, Schols L, Riess O: Ala30Pro mutation in the gene encoding a-synuclein in Parkinson's disease. Nat Genet 1998, 18:106-108.

5. Polymeropoulos MH, Lavedan C, Leroy E, Idle SE, Dehejia A, Dutra A, Pike B, Root H, Rubenstein J, Boyer R, et al: Mutation in the a-Synuclein gene identified in families with Parkinson's disease. Science 1997. 276:2045-2047.

6. Zarranz JJ, Alegre J, Gomez-Esteban JC, Lezcano E, Ros R, Ampuero I, Vidal L, Hoenicka J, Rodriguez O, Atares B, et al: The new mutation, E46K, of alpha-synuclein causes Parkinson and Lewy body dementia. Ann Neurol 2004, 55(2):164-173.

7. Irizarry MC, Growdon W, Gomez-Isla T, Newell K, George JM, Clayton DF, Hyman BT: Nigral and cortical Lewy bodies and dystrophic nigral neurites in Parkinson's disease and cortical Lewy body disease contain alpha-synuclein immunoreactivity. J Neuropathol Exp Neurol 1998, 57(4):334-337.

8. Braak H, Del Tredici K, Rub U, de Vos RA, Jansen Steur EN, Braak E: Staging of brain pathology related to sporadic Parkinson's disease. Neurobiology of aging 2003, 24(2):197-211.

9. Auluck PK, Chan HYE, Trojanowski JQ, Lee VM-Y, Bonini NM: Chaperone suppression of a-synuclein toxicity in a Drosophila model for Parkinson's disease. Science 2002, 295:865-868.

10. Bodner RA, Outeiro TF, Altmann S, Maxwell MM, Cho SH, Hyman BT, McLean PJ, Young AB, Housman DE, Kazantsev AG: Pharmacological promotion of inclusion formation: a therapeutic approach for Huntington's and Parkinson's diseases. Proc Natl Acad Sci U S A 2006, 103(11):4246-4251.

11. Bucciantini M, Calloni G, Chiti F, Formigli L, Nosi D, Dobson CM, Stefani M: Prefibrillar amyloid protein aggregates share common features of cytotoxicity. J Biol Chem 2004, 279(30):31374-31382.

12. El-Agnaf OM, Salem SA, Paleologou KE, Curran MD, Gibson MJ, Court JA, Schlossmacher MG, Allsop D: Detection of oligomeric forms of alphasynuclein protein in human plasma as a potential biomarker for Parkinson's disease. FASEB J 2006, 20(3):419-425.

13. Kayed R, Head E, Thompson JL, McIntire TM, Milton SC, Cotman CW, Glabe CG: Common structure of soluble amyloid oligomers implies common mechanism of pathogenesis. Science 2003, 300(5618):486-489.

14. Lashuel HA, Petre BM, Wall J, Simon M, Nowak RJ, Walz T, Lansbury PT Jr: Alpha-synuclein, especially the Parkinson's disease-associated mutants, forms pore-like annular and tubular protofibrils. J Mol Biol 2002, 322(5):1089-1102.

15. Masliah E, Rockenstein E, Veinbergs I, Mallory M, Hashimoto M, Takeda A, Sagara Y, Sisk A, Mucke L: Dopaminergic loss and inclusion body formation in a-synuclein mice: Implications for neurodegenerative disorders. Science 2000, 287:1265-1269.

16. Desplats P, Lee HJ, Bae EJ, Patrick C, Rockenstein E, Crews L, Spencer B, Masliah E, Lee SJ: Inclusion formation and neuronal cell death through neuron-to-neuron transmission of alpha-synuclein. Proc Natl Acad Sci U S A 2009, 106(31):13010-13015.

17. Danzer KM, Ruf WP, Putcha P, Joyner D, Hashimoto T, Glabe C, Hyman BT, McLean PJ: Heat Shock Protein 70 modulates toxic extracellular alpha-synuclein oligomers and rescues trans-synaptic toxicity. FASEB $J$ 2010, In Press.

18. Ahn KJ, Paik SR, Chung KC, Kim J: Amino acid sequence motifs and mechanistic features of the membrane translocation of alpha-synuclein. J Neurochem 2006, 97(1):265-279.

19. Danzer KM, Haasen D, Karow AR, Moussaud S, Habeck M, Giese A, Kretzschmar H, Hengerer B, Kostka M: Different species of alpha-synuclein oligomers induce calcium influx and seeding. J Neurosci 2007, 27(34):9220-9232.

20. Danzer KM, Krebs SK, Wolff M, Birk G, Hengerer B: Seeding induced by alpha-synuclein oligomers provides evidence for spreading of alpha-synuclein pathology. J Neurochem 2009, 111(1):192-201.

21. Lee HJ, Suk JE, Bae EJ, Lee JH, Paik SR, Lee SJ: Assembly-dependent endocytosis and clearance of extracellular alpha-synuclein. Int J Biochem Cell Biol 2008, 40(9):1835-1849.

22. Luk KC, Song C, O'Brien P, Stieber A, Branch JR, Brunden KR, Trojanowski JQ, Lee VM: Exogenous alpha-synuclein fibrils seed the formation of Lewy body-like intracellular inclusions in cultured cells. Proc Natl Acad Sci U S A 2009, 106(47):20051-20056

23. Emmanouilidou E, Melachroinou K, Roumeliotis T, Garbis SD, Ntzouni M, Margaritis $L H$, Stefanis L, Vekrellis K: Cell-produced alpha-synuclein is secreted in a calcium-dependent manner by exosomes and impacts neuronal survival. J Neurosci, 30(20):6838-6851.

24. Alvarez-Erviti L, Seow Y, Schapira AH, Gardiner C, Sargent IL, Wood MJ, Cooper JM: Lysosomal dysfunction increases exosome-mediated alphasynuclein release and transmission. Neurobiol Dis 2011, 42(3):360-367.

25. Outeiro TF, Putcha P, Tetzlaff JE, Spoelgen R, Koker M, Carvalho F, Hyman BT, McLean PJ: Formation of toxic oligomeric alpha-synuclein species in living cells. PLoS One 2008, 3(4):e1867.

26. Putcha P, Danzer KM, Kranich LR, Scott A, Silinski M, Mabbett S, Hicks CD, Veal JM, Steed PM, Hyman BT, et al: Brain permeable small molecule inhibitors of Hsp90 prevent alpha-synucleinoligomer formation and rescue alpha-synuclein-induced toxicity. J Pharmacol Exp Ther 2009, in press.

27. Remy I, Michnick SW: A cDNA library functional screening strategy based on fluorescent protein complementation assays to identify novel components of signaling pathways. Methods 2004, 32(4):381-388.

28. Remy I, Michnick SW: A highly sensitive protein-protein interaction assay based on Gaussia luciferase. Nat Methods 2006, 3(12):977-979.

29. St Martin JL, Klucken J, Outeiro TF, Nguyen P, Keller-McGandy C, Cantuti-Castelvetri I, Grammatopoulos TN, Standaert DG, Hyman BT, McLean PJ: Dopaminergic neuron loss and up-regulation of chaperone protein mRNA induced by targeted over-expression of alpha-synuclein in mouse substantia nigra. J Neurochem 2007, 100(6):1449-1457.

30. Tetzlaff JE, Putcha P, Outeiro TF, Ivanov A, Berezovska O, Hyman BT, McLean PJ: CHIP targets toxic alpha-Synuclein oligomers for degradation. J Biol Chem 2008, 283(26):17962-17968.

31. Lee HJ, Patel S, Lee SJ: Intravesicular localization and exocytosis of alpha-synuclein and its aggregates. J Neurosci 2005, 25(25):6016-6024.

32. Mollenhauer B, Cullen V, Kahn I, Krastins B, Outeiro TF, Pepivani I, Ng J, Schulz-Schaeffer W, Kretzschmar HA, McLean PJ, et al: Direct quantification of CSF alpha-synuclein by ELISA and first cross-sectional study in patients with neurodegeneration. Exp Neurol 2008, 213(2):315-325.

33. Sung JY, Kim J, Paik SR, Park JH, Ahn YS, Chung KC: Induction of neuronal cell death by Rab5A-dependent endocytosis of alpha-synuclein. J Biol Chem 2001, 276(29):27441-27448

34. Fevrier B, Vilette D, Archer F, Loew D, Faigle W, Vidal M, Laude H, Raposo G: Cells release prions in association with exosomes. Proc Natl Acad Sci U S A 2004, 101(26):9683-9688.

35. Thery C, Amigorena S, Raposo G, Clayton A: Isolation and characterization of exosomes from cell culture supernatants and biological fluids. Curr Protoc Cell Biol 2006, Chapter 3:Unit 322.

36. Escola JM, Kleijmeer MJ, Stoorvogel W, Griffith JM, Yoshie O, Geuze HJ: Selective enrichment of tetraspan proteins on the internal vesicles of multivesicular endosomes and on exosomes secreted by human B-lymphocytes. J Biol Chem 1998, 273(32):20121-20127.

37. Simpson RJ, Lim JW, Moritz RL, Mathivanan S: Exosomes: proteomic insights and diagnostic potential. Expert Rev Proteomics 2009, 6(3):267-283.

38. Schultz J, Lorenz P, Gross G, Ibrahim S, Kunz M: MicroRNA let-7b targets important cell cycle molecules in malignant melanoma cells and interferes with anchorage-independent growth. Cell Res 2008, 18(5):549-557.

39. Taylor DD, Gercel-Taylor C: MicroRNA signatures of tumor-derived exosomes as diagnostic biomarkers of ovarian cancer. Gynecol Oncol 2008, 110(1):13-21.

40. Valadi H, Ekstrom K, Bossios A, Sjostrand M, Lee JJ, Lotvall JO: Exosomemediated transfer of mRNAs and microRNAs is a novel mechanism of genetic exchange between cells. Nat Cell Biol 2007, 9(6):654-659. 
41. Chen XM, Splinter PL, O'Hara SP, LaRusso NF: A cellular micro-RNA, let-7i, regulates Toll-like receptor 4 expression and contributes to cholangiocyte immune responses against Cryptosporidium parvum infection. J Biol Chem 2007, 282(39):28929-28938.

42. Segura MF, Hanniford D, Menendez S, Reavie L, Zou X, Alvarez-Diaz S, Zakrzewski J, Blochin E, Rose A, Bogunovic D, et al: Aberrant miR-182 expression promotes melanoma metastasis by repressing $\mathrm{FOXO} 3$ and microphthalmia-associated transcription factor. Proc Natl Acad Sci U S A 2009, 106(6):1814-1819.

43. Weitzel RP, Lesniewski ML, Haviernik P, Kadereit S, Leahy P, Greco NJ, Laughlin MJ: microRNA 184 regulates expression of NFAT1 in umbilical cord blood CD4+ T cells. Blood 2009, 113(26):6648-6657.

44. Bentwich I, Avniel A, Karov Y, Aharonov R, Gilad S, Barad O, Barzilai A, Einat $P$, Einav $U$, Meiri $E$, et al: Identification of hundreds of conserved and nonconserved human microRNAs. Nat Genet 2005, 37(7):766-770.

45. Sewer A, Paul N, Landgraf P, Aravin A, Pfeffer S, Brownstein MJ, Tuschl T, van Nimwegen E, Zavolan M: Identification of clustered microRNAs using an ab initio prediction method. BMC Bioinforma 2005, 6:267

46. Huang Q, Gumireddy K, Schrier M, le Sage C, Nagel R, Nair S, Egan DA, Li A, Huang G, Klein-Szanto AJ, et al: The microRNAs miR-373 and miR-520c promote tumour invasion and metastasis. Nat Cell Biol 2008, 10(2):202-210.

47. Altuvia $Y$, Landgraf $P$, Lithwick $G$, Elefant N, Pfeffer S, Aravin A, Brownstein MJ, Tuschl T, Margalit $\mathrm{H}$ : Clustering and conservation patterns of human microRNAs. Nucleic Acids Res 2005, 33(8):2697-2706.

48. Kawahara $Y$, Zinshteyn $B$, Sethupathy $P$, lizasa $H$, Hatzigeorgiou AG, Nishikura K: Redirection of silencing targets by adenosine-to-inosine editing of miRNAs. Science 2007, 315(5815):1137-1140.

49. Rosa A, Ballarino M, Sorrentino A, Sthandier O, De Angelis FG, Marchioni M, Masella B, Guarini A, Fatica A, Peschle C, et al: The interplay between the master transcription factor PU.1 and miR-424 regulates human monocyte/macrophage differentiation. Proc Natl Acad Sci U S A 2007, 104(50):19849-19854.

50. Wheeler G, Ntounia-Fousara S, Granda B, Rathjen T, Dalmay T: Identification of new central nervous system specific mouse microRNAs. FEBS Lett 2006, 580(9):2195-2200.

51. Ujifuku K, Mitsutake N, Takakura S, Matsuse M, Saenko V, Suzuki K, Hayashi K, Matsuo T, Kamada K, Nagata I, et al: miR-195, miR-455-3p and miR-10a( *) are implicated in acquired temozolomide resistance in glioblastoma multiforme cells. Cancer Lett 2010, 296(2):241-248.

52. Goodarzi $\mathrm{H}$, Elemento $\mathrm{O}$, Tavazoie S: Revealing global regulatory perturbations across human cancers. Mol Cell 2009, 36(5):900-911.

53. Liu L, Jiang $Y$, Zhang $H$, Greenlee AR, Han Z: Overexpressed miR-494 down-regulates PTEN gene expression in cells transformed by antibenzo(a)pyrene-trans-7,8-dihydrodiol-9,10-epoxide. Life Sci, 86(5-6):192-198

54. Landgraf $P$, Rusu M, Sheridan R, Sewer A, lovino N, Aravin A, Pfeffer S, Rice A, Kamphorst AO, Landthaler M, et al: A mammalian microRNA expression atlas based on small RNA library sequencing. Cell 2007, 129(7):1401-1414.

55. Zhu H, Wu H, Liu X, Evans BR, Medina DJ, Liu CG, Yang JM: Role of MicroRNA miR-27a and miR-451 in the regulation of MDR1/Pglycoprotein expression in human cancer cells. Biochem Pharmacol 2008, 76(5):582-588

56. Girardot M, Pecquet C, Boukour S, Knoops L, Ferrant A, Vainchenker W, Giraudier S, Constantinescu SN: miR-28 is a thrombopoietin receptor targeting microRNA detected in a fraction of myeloproliferative neoplasm patient platelets. Blood 2010, 116(3):437-445.

57. Tazawa H, Tsuchiya N, Izumiya M, Nakagama H: Tumor-suppressive miR$34 \mathrm{a}$ induces senescence-like growth arrest through modulation of the E2F pathway in human colon cancer cells. Proc Natl Acad Sci U S A 2007, 104(39):15472-15477.

58. Petrocca F, Vecchione A, Croce CM: Emerging role of miR-106b-25/miR17-92 clusters in the control of transforming growth factor beta signaling. Cancer Res 2008, 68(20):8191-8194.

59. Takahashi Y, Forrest AR, Maeno E, Hashimoto T, Daub CO, Yasuda J: MiR107 and MiR-185 can induce cell cycle arrest in human non small cell lung cancer cell lines. PLoS One 2009, 4(8):e6677.

60. Song B, Wang Y, Kudo K, Gavin EJ, Xi Y, Ju J: miR-192 Regulates dihydrofolate reductase and cellular proliferation through the p53-microRNA circuit. Clin Cancer Res 2008, 14(24):8080-8086.
61. Chao A, Tsai CL, Wei PC, Hsueh S, Chao AS, Wang CJ, Tsai CN, Lee YS, Wang TH, Lai CH: Decreased expression of microRNA-199b increases protein levels of SET (protein phosphatase $2 \mathrm{~A}$ inhibitor) in human choriocarcinoma. Cancer Lett, 291(1):99-107.

62. Barroso-delJesus A, Romero-Lopez C, Lucena-Aguilar G, Melen GJ, Sanchez L, Ligero G, Berzal-Herranz A, Menendez P: Embryonic stem cell-specific miR302-367 cluster: human gene structure and functional characterization of its core promoter. Mol Cell Biol 2008, 28(21):6609-6619.

63. Xie X, Lu J, Kulbokas EJ, Golub TR, Mootha V, Lindblad-Toh K, Lander ES, Kellis M: Systematic discovery of regulatory motifs in human promoters and 3' UTRs by comparison of several mammals. Nature 2005, 434(7031):338-345.

64. Nakano H, Miyazawa T, Kinoshita K, Yamada Y, Yoshida T: Functional screening identifies a microRNA, miR-491 that induces apoptosis by targeting $\mathrm{Bcl}-\mathrm{X}(\mathrm{L})$ in colorectal cancer cells. Int J Cancer 2009, 127(5):1072-1080.

65. Roshan R, Ghosh T, Scaria V, Pillai B: MicroRNAs: novel therapeutic targets in neurodegenerative diseases. Drug Discov Today 2009, 14(23-24):1123-1129.

66. Junn E, Lee KW, Jeong BS, Chan TW, Im JY, Mouradian MM: Repression of alpha-synuclein expression and toxicity by microRNA-7. Proc Natl Acad Sci U S A 2009, 106(31):13052-13057.

67. Zhang W, Wang T, Pei Z, Miller DS, Wu X, Block ML, Wilson B, Zhou Y, Hong JS, Zhang J: Aggregated alpha-synuclein activates microglia: a process leading to disease progression in Parkinson's disease. FASEB J 2005, 19(6):533-542

68. Tian T, Wang $Y$, Wang $H$, Zhu Z, Xiao Z: Visualizing of the cellular uptake and intracellular trafficking of exosomes by live-cell microscopy. J Cell Biochem 2010, 111(2):488-496.

69. Stoeckl L, Funk A, Kopitzki A, Brandenburg B, Oess S, Will H, Sirma H, Hildt E: Identification of a structural motif crucial for infectivity of hepatitis $B$ viruses. Proc Natl Acad Sci U S A 2006, 103(17):6730-6734.

70. Keller S, Ridinger J, Rupp AK, Janssen JW, Altevogt P: Body fluid derived exosomes as a novel template for clinical diagnostics. Journal of translational medicine 2011, 9:86.

71. Papahadjopoulos D, Miller N: Phospholipid model membranes. I. Structural characteristics of hydrated liquid crystals. Biochim Biophys Acta 1967, 135(4):624-638.

72. Denzer K, Kleijmeer MJ, Heijnen HF, Stoorvogel W, Geuze HJ: Exosome: from internal vesicle of the multivesicular body to intercellular signaling device. J Cell Sci 2000, 113(Pt 19):3365-3374

73. Johnstone RM: Exosomes biological significance: A concise review. Blood cells, molecules \& diseases 2006, 36(2):315-321.

74. Mathivanan S, Ji H, Simpson RJ: Exosomes: extracellular organelles important in intercellular communication. Journal of proteomics 2010, 73(10):1907-1920.

75. Fader CM, Sanchez D, Furlan M, Colombo Ml: Induction of autophagy promotes fusion of multivesicular bodies with autophagic vacuoles in k562 cells. Traffic 2008, 9(2):230-250.

76. Klionsky DJ, Abeliovich H, Agostinis P, Agrawal DK, Aliev G, Askew DS, Baba M, Baehrecke EH, Bahr BA, Ballabio A, et al: Guidelines for the use and interpretation of assays for monitoring autophagy in higher eukaryotes. Autophagy 2008, 4(2):151-175.

77. Faure J, Lachenal G, Court M, Hirrlinger J, Chatellard-Causse C, Blot B, Grange J, Schoehn G, Goldberg Y, Boyer V, et al: Exosomes are released by cultured cortical neurones. Mol Cell Neurosci 2006, 31(4):642-648.

78. van Niel G, Porto-Carreiro I, Simoes S, Raposo G: Exosomes: a common pathway for a specialized function. J Biochem 2006, 140(1):13-21.

79. Vella $\amalg$, Sharples RA, Lawson VA, Masters CL, Cappai R, Hill AF: Packaging of prions into exosomes is associated with a novel pathway of $\operatorname{PrP}$ processing. J Pathol 2007, 211(5):582-590.

80. Rajendran L, Honsho M, Zahn TR, Keller P, Geiger KD, Verkade P, Simons K Alzheimer's disease beta-amyloid peptides are released in association with exosomes. Proc Natl Acad Sci U S A 2006, 103(30):11172-11177.

81. Ghidoni R, Benussi L, Binetti G: Exosomes: the Trojan horses of neurodegeneration. Med Hypotheses 2008, 70(6):1226-1227.

82. Hasegawa T, Konno M, Baba T, Sugeno N, Kikuchi A, Kobayashi M, Miura E, Tanaka N, Tamai K, Furukawa K, et al: The AAA-ATPase VPS4 regulates extracellular secretion and lysosomal targeting of alpha-synuclein. PLOS One 2011, 6(12):e29460. 
83. de Gassart A, Geminard C, Fevrier B, Raposo G, Vidal M: Lipid raftassociated protein sorting in exosomes. Blood 2003, 102(13):4336-4344.

84. Fortin DL, Troyer MD, Nakamura K, Kubo S, Anthony MD, Edwards RH: Lipid rafts mediate the synaptic localization of alpha-synuclein. J Neurosci 2004, 24(30):6715-6723.

85. Kubo S, Nemani VM, Chalkley RJ, Anthony MD, Hattori N, Mizuno Y, Edwards $\mathrm{RH}$, Fortin DL: A combinatorial code for the interaction of alpha-synuclein with membranes. J Biol Chem 2005, 280(36):31664-31672.

86. Pfefferkorn CM, Heinrich F, Sodt AJ, Maltsev AS, Pastor RW, Lee JC: Depth of alpha-Synuclein in a Bilayer Determined by Fluorescence, Neutron Reflectometry, and Computation. Biophys J 2012, 102(3):613-621.

87. Aguzzi $A$, Rajendran $\mathrm{L}$ : The transcellular spread of cytosolic amyloids, prions, and prionoids. Neuron 2009, 64(6):783-790

88. Fang Y, Wu N, Gan X, Yan W, Morrell JC, Gould SJ: Higher-order oligomerization targets plasma membrane proteins and HIV gag to exosomes. PLoS Biol 2007, 5(6):e158

89. Perrin RJ, Woods WS, Clayton DF, George JM: Exposure to long chain polyunsaturated fatty acids triggers rapid multimerization of synucleins. J Biol Chem 2001, 276(45):41958-41962.

90. Hughes RC: Secretion of the galectin family of mammalian carbohydratebinding proteins. Biochim Biophys Acta 1999, 1473(1):172-185.

91. Mehul B, Hughes RC: Plasma membrane targetting, vesicular budding and release of galectin 3 from the cytoplasm of mammalian cells during secretion. J Cell SCi 1997, 110(Pt 10):1169-1178.

92. Liu J, Zhang JP, Shi M, Quinn T, Bradner J, Beyer R, Chen S, Zhang J: Rab11a and HSP90 regulate recycling of extracellular alpha-synuclein. $J$ Neurosci 2009, 29(5):1480-1485.

93. Fevrier B, Raposo G: Exosomes: endosomal-derived vesicles shipping extracellular messages. Curr Opin Cell Biol 2004, 16(4):415-421.

94. Ratajczak J, Wysoczynski M, Hayek F, Janowska-Wieczorek A, Ratajczak MZ: Membrane-derived microvesicles: important and underappreciated mediators of cell-to-cell communication. Leukemia 2006, 20(9):1487-1495.

95. Keller S, Sanderson MP, Stoeck A, Altevogt P: Exosomes: from biogenesis and secretion to biological function. Immunol Lett 2006, 107(2):102-108.

96. Thery C, Zitvogel L, Amigorena S: Exosomes: composition, biogenesis and function. Nat Rev Immunol 2002, 2(8):569-579.

97. Vincent JP, Magee T: Argosomes: membrane fragments on the run. Trends Cell Biol 2002, 12(2):57-60.

98. Inouye $\mathrm{H}$, Kirschner DA: Alzheimer's beta-amyloid: insights into fibril formation and structure from Congo red binding. Subcell Biochem 2005, 38:203-224.

99. Sanchez I, Mahlke C, Yuan J: Pivotal role of oligomerization in expanded polyglutamine neurodegenerative disorders. Nature 2003, 421(6921):373-379.

100. Rubinsztein DC, Gestwicki JE, Murphy LO, Klionsky DJ: Potential therapeutic applications of autophagy. Nat Rev Drug Discov 2007, 6(4):304-312.

101. Bandyopadhyay U, Cuervo AM: Chaperone-mediated autophagy in aging and neurodegeneration: lessons from alpha-synuclein. Exp Gerontol 2007, 42(1-2):120-128

102. Bennett MC, Bishop JF, Leng Y, Chock PB, Chase TN, Mouradian MM: Degradation of a-synuclein by the proteasome. J Biol Chem 1999, 274(48):33855-33858.

103. Vogiatzi T, Xilouri M, Vekrellis K, Stefanis L: Wild type alpha-synuclein is degraded by chaperone-mediated autophagy and macroautophagy in neuronal cells. J Biol Chem 2008, 283(35):23542-23556.

104. Webb JL, Ravikumar B, Atkins J, Skepper JN, Rubinsztein DC: Alpha-Synuclein is degraded by both autophagy and the proteasome. J Biol Chem 2003, 278(27):25009-25013.

105. Yamamoto A, Tagawa Y, Yoshimori T, Moriyama Y, Masaki R, Tashiro Y: Bafilomycin A1 prevents maturation of autophagic vacuoles by inhibiting fusion between autophagosomes and lysosomes in rat hepatoma cell line, H-4-II-E cells. Cell Struct Funct 1998, 23(1):33-42.

doi:10.1186/1750-1326-7-42

Cite this article as: Danzer et al:: Exosomal cell-to-cell transmission of alpha synuclein oligomers. Molecular Neurodegeneration 2012 7:42.

\section{Submit your next manuscript to BioMed Central and take full advantage of:}

- Convenient online submission

- Thorough peer review

- No space constraints or color figure charges

- Immediate publication on acceptance

- Inclusion in PubMed, CAS, Scopus and Google Scholar

- Research which is freely available for redistribution

Submit your manuscript at www.biomedcentral.com/submit
Biomed Central 